UNIVERSIDAD NACIOUAL DE LA PLATA

$$
\text { FACULTAD DE QUIMICA Y FARMACIA }
$$

"DETERRIIIACION CUANIITATIVA DE

PEC T I IN A S

EN SEUTLLA DE LINO"

IIÉctor P.Artinda.

1948.- 
En cumplimlento del artículo 88 del roglam de esta Facultad, a fin de optar al titulo de doctor en Ble y Farmacla,someto a ruestra considerqción el presente traba tema de tesis, desarrollado de acuerdo al sigaiente plan "DETERMIFACION CUANTITATIVA DE PECTINA EN SEMILLA DE LTHÓ Parte Teorica. CAPITULO I.

Introducción.Nonenclatura.

Localización

constitución.-

\section{PARTE PRATICA}

CAFITULO II

Muestras:su origen.

Preparación de la musstra

sxtraceión

Determiración cuartitativa.-

\section{CAPITULU III}

Extraccion de pectina

Purificación

Ensayos

Conclusiones.

Bigliografla.

Ia finalidad principal de este trabajo ha sido determina nido de pectina de las distintas parledades de semillas probadas por el iilnisterio de Agricultura de la Nación,co bien veriflcar, de acuerdo a las variaciones de su fluencia que pudieran efercer las factores relna: tivas zonas de cultivo,tales conr suelo, clima,etc.Con el fin de ut1lizar el método más oxacto para la de: de estas ustanclas, se ha agotado, dentro de 10 posibie, clón existente al respecto,como as tamblen se ha recu confrontación experimental; tanto de los agentes ext 
de los principales metodos de evaluación propuestos.Ia parte experimental de esto trabajo, ha sido realizar en el Instituto de Investigaciones" Psoresor Dr. Carlus A.Sagastume" a cuyo personal, tanto directivo como subalterno, deseo expresar mi más sentido agradeclifento por el apoyp clentifico y moral que constante $y$ deferentemente me brindaron en el largo lapso de año $y$ medio,al par que reconocer que parte de este urabajo ha sido realidad merced a la Inestimable cooperación del isr.Jefe de Electro. qufmica y compañero de tcdos los dias,Dr.Harcelo Galar.Y para finalizar,solo me resta reconocerle y agradecerle al caba. lleresco asesor clentifico Dr.Carlos HAlbizzatl,gestor del presente trabajo y a cuyo servicio dedlco solicltamente,obviando molestias y al cual brindo behévolamente quizá, el espaldarazn ral de su visto bueno.- 
ASESOR CIENTIFICO

\section{Profesor}

Ing . Dr .CARLOS M.ALBIZZATI 
A Ia nemorla de mi madre.A los mios.- 


\section{CAPTTULO I \\ PAATE TEOORICA, - INTRODUCCION

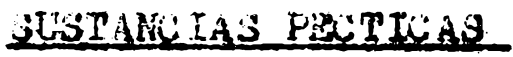

Ias sustanclas pécticas, pertenecientes al grupo de los carbohldratos derivativos, fueron descublertas por Braconnot en 1825, descubri miento que fué confirmado por Payen,mediante su extracción de la ralz del Allanthus glandulosa.-

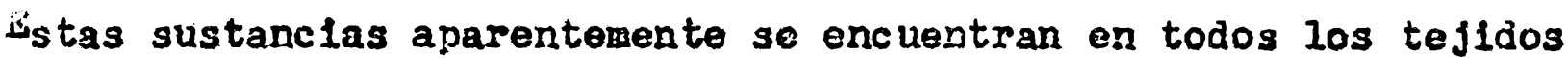
vegetales,especialmente en los frutos,y a cuya presencla deben est tos su tiplea propledad de formar jaleas.la presencla de estas sus tanclas on 103 tejidos vegetales indujo a botánicos y quimicos a investigar tanto su localización y rol quie desenpeñan durante el transcurso de la vida de los mismos, coino tambien su extracelón composicion $y$ determinación quimica,y si:s propiedades cololdales que ya fueron señaladas en 1840 por Fremy.-

Ya desdo las primeros trabajos se distinguieron las distintas mo dificaciones, con respecto a su solublildad, que presentan las sustanclas pécticas.-Asf, fremy designó con el nombre de pectosa a las sustancias pécticas insolubles, las cuales durante el proceso de ciuración o por tratamiento a ebullición con acidos dilufdos generaban dos variedades solubles.ta parapectina,que era preclpitada por el acotato deutro de $\mathrm{Pb}$ y la metapectina que era procipltada por el $\mathrm{Cl}_{2} \mathrm{Ca}$.-

Por otra parte, Ehrlich afirmaba la heteroceneidad de la pectlna de distintos origenes,es decir que las distintas pectinas estarien corstituidas bajo un plan general pero con varlables cantidades de unidades constituyentes, mientras que nimerosisimos autores sostienen que no existen payores diferenclas en las pectinas de diversos orfgenes y que estas diferencias se deberían,posiblemente, a las modificaciones que se producen durante el proceso de extraoción.-

Generalmente se admite que el nicleo fundamental de las sustanclas péctlcas está forciado por el ácido péctico,el eual esta constitildo por unidades de áctdo poligalacturónico contenlento en adicion alguno o algunos azúcares.-

En el transclirso def tiempo, distintas teorlas se han emiticio para exnlicar la constitrición dol ácida.péctico, muchas de las cuales - 
no pueden ser aceptadas en la actialedąd,tales como la de thrIich o del ácido totragalacturónico, la de ialfi-Pattok y king, etc.debido a las conclusiones a que han liegado bink, schneider y colaboradores.- 


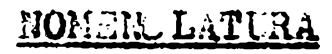

Durante el transcurso del estudio de las sustanclas pécticas ha $31-$ do, muchas veces, diffcil valorar proplämente y coordinar las conclusio nes seifaladas por los distlitos investicadores, debido a que estas sustanclas,sus productos de hidrólisis y slis enzimas eran designadas bajo nomenclaturas arbitrarlamente elefidas y aún bajo nomerclaturas'. proplas, como en el caso de Ehrlich.-

En el presente trabajo se adoptó la nomericlatura recomendada por la.jocledad juimica dmericana(89) con las modiflcaclonss introducidas para su actrallzación en el año 1943(90) y que es la sigulente:

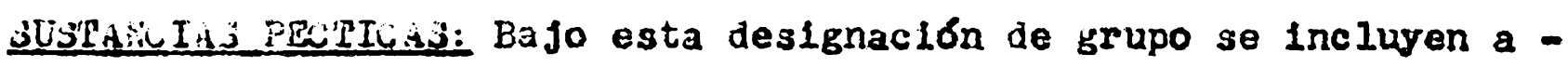
aquelios carbohldratos derivativos, complejos, de naturaleza cololdal rilie se encientran o son extrafdos de plantas y que se caracterizan por le presencla de unidades de ácldos anhidrogalacturonico en su molécula, los cuales, posiblemente se encuentran anidos en forma de catera.-

Ezte Scicio complejo está asoclado a unldades de arabinosa y galactrsa y sus grupos carboxilos pueder hallarse libres o neutral1zados, parcial o totalmente, com: sal netálica, pero más generalmente como ester metilico.-

interiormente, a todas estas sustanclas se ias designaban generalmente con el nombre de "pectinas" diferenciándose unas de otras por su diferente solubilidad de H2O.-Laego esta designación de grupo fue reenplazada :or la de "sustanclas péctica 3 " 5 l término "pecti:a" ha sldo restringldo para designar únicaterite a ias sustancias pect1cas metoxiladas y solubles en $\mathrm{H}, 0$.-

il término "carbohidrato derlvativo" es empleado para diferenciar a estas sustancias de les polisacaridos en general, ya que aqueilas sustancias ise distinguen de estas ultimas por la presencla de gropos barboxilos en su molécula, los cuales, posiblemente, se han or 1g1najo por oxidación de los grupos alconolicos de los azucares.La palabra "cololdai" ha sido añadida para excluir de ésta denominación a tolas aquellas slistariclas pécticas que han perdido slis propiedades cololdales,ya sea nor descomposición o por degradación.Originalmente las justanclas pécticas contfre: unidades de arabundsa y galactosa pero,por efecto del tratamiento durante el proceso - 
de extracclón,pueden ser parclal o totalmente allminadis, como tamblen,por la misma causa,puede disminuir el porcentaje de los grupos esteres metIIIcos.-

PROTOPqIINA: El término protopectina es aplicado a las sustancias. pectinas Insolbbles en H20, las cuales ee encuentran en plantas y qle, por hidrólisis restringldae, da origen a la pectina y ácldos pectinlcos.-

ista sustancia pectica original, en el transcurso del tlempo, ha sido designada bajo diferentes nombres,asi,freny en 1840 la 11 amó "pectosa", Tschirch en 1908 "protopectina" y Jchryver en 1914 "pectinogeno"--Durante mucho tleapo prevaleció para la designación de esta sustancla el término "pectosa" hasta qlie Tschirch propuso el de "protopectina" que rué aceptado por numerosos investlgadores y que,posteriormente, ha sido ofichlizado por el comité de la sociedad quimlca imerlcana.-

ACIDOS PBCIRICOj:Bajo esta designación se Incluyen a las sustianclas pecticas constituldas por acidos poligalacturenicos colo1dxles que contienen una pequeña proporción de esteres metillcos.-ìstos ácidos pectínicos, bajo convenientes condiclones, tienen la propledad de formar geles con azúcar y áclios,y tamblen, 31 el conten1do de ester metilico es redicido, con clertos lones motálicos.:Los acidos pectinicos pueden dar lugar a la formadón de sales neutras y sales ácidas;a estas ultimas sales conjuntamente con las aclios pectinicos, comercialmente, se les designa con el nombre de "pectina no dilulda"

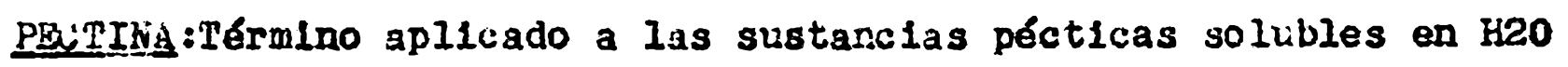
de varlable grado de neutralización y contenido le esteres metillcos que $3 e$ encuentra en los tefidos de plartas o que puede der preparada por tratamiento restringido de la protopectina con la enzima protopectinasa,ácilos u otres reactivos.-

La petina tiene la propledad de dar,por dispereión en $\mathrm{H20}$, un sol cololdal viscoso del cual papde ser preclpitada por medio del alcohol etilico,acetona y sales de tales pesados,tales como el Fe. $\mathrm{Pb}$. Al.etc.y además se caracteriza por su capacidad de formar geles bajo convenlentes condiclonos, con azucar y acldo.-

isipos pirruas: con este término se destgran a las stistancias pec- 
ticas compuestas de acidos poligalacturanicos coloidales y que esenelaliente no continen grupos grupos esteres motilicos en su molecula. EI término "colotdal" se explea para exclulr de esta designación a todos aquellos qcidos poligalacturb́nicos que contimenen pocas unidades de ácldo anhldrogalacturónlco y que no presentan las propledades cololdales que caracterizan a las sustanclas pécticas.-

La expresión "que esenclaimente no contienen grupos esteres metillcos" se justiflca por la razón de que on todas las preparaclones de ácldo péctico se han encontrado slempre pequer̃as cantidades de grupos esteres metIIlcos, $(0,2$ a $0.8 \%)$ no conocléndose hasta el presente el signi flcado de su presercia.-

PROTOPECTIRSA: Tómine que je apllca para designar a la enzlma que hidrolisa a la protopectina a pectina, produclendo la consigulente separación eri los tejldos de la planta.-

A esta enzima,antiguaminte,se la designaba con el nombre de "pectosinasa".-

PECTAja:Tármino que designa a la enzima que actna sobre la pectina con virtiéndola en ácldo péctico, el cual en presericia de clertas salesti(ca.Da.Sr.etc.) puede producir geles,los cuales postblemente se deberlan al efecto coggulante de la enzima.-

PETOSINA广A : Tórmino aplicado a la enzlma que acta sobre la pectina y ácido péctico hldrolizándolics a sus simples componentes, 108 auples son probablezente arabinosa,galactosa y ácido galacturónico.-

A cont Inuacion se transcriben los sinónimos citados por la Socledad ưfilca Americana:

\begin{tabular}{|c|c|c|}
\hline Actual destangcion & Nombre antertor & Autor \\
\hline \multirow[t]{8}{*}{ PROTOPELTINA } & Protopectina & Tschiroh \\
\hline & $i \operatorname{ectina}$ & Braconnot \\
\hline & Pectosa & Frems \\
\hline & Pectinogeno & $\begin{array}{c}\text { Norris y Bchey } \\
\text { rer. }\end{array}$ \\
\hline & Pectocelulosa & Cross \\
\hline & Ifgiocelulosa & Cross \\
\hline & Poctina original & Ehrlich \\
\hline & Urpectin & Bhrlich \\
\hline
\end{tabular}




\begin{tabular}{|c|c|c|}
\hline Acturl destracion & Nombre anterior & sutor: \\
\hline PEGTINA I ACIDOS & Acldo pectoilco & Prom \\
\hline \multirow[t]{5}{*}{ PECTINICOS } & HidratopectIna & Earilch \\
\hline & Pectina 11bre & Sucharipa \\
\hline & Acido péctico & Inink \\
\hline & "Rohpakt In" & Ehrlech \\
\hline & Pectina solubre & Muchos au \\
\hline \multicolumn{3}{|l|}{ PECTIMA DEGENRRADA } \\
\hline \multirow[t]{3}{*}{ б ACIDOS PBTIHICOS } & Hetapectina & Prems \\
\hline & Parapectina & Premy \\
\hline & Acldo perpéct1co & Choanew \\
\hline \multicolumn{3}{|l|}{$A C \cdot P E C T I C O Y$ YCIDO } \\
\hline \multirow[t]{3}{*}{ POLIGALACTLRONICO } & Pectina & Promy \\
\hline & Ac.citopect1co & Clayson \\
\hline & Ac. Pectós1co & Frem \\
\hline ALATICOS Y ACIDOS & Ac. parapéctico & Fremy \\
\hline POLIGALACTLROIISOS & Ac.metapéct1co & Freng \\
\hline \multirow[t]{5}{*}{ D:GENRYADOS.- } & Ac alpectico & Bhrlich \\
\hline & "Gel. Pektolsaunre" & Ehrlich \\
\hline & "Pektolsaure" & E:Irlich \\
\hline & Ac.digalacturonicos & Ehrilch \\
\hline & $\begin{array}{l}\text { Ac.tetragalacturanicos } \\
\text { a-Bjc- }\end{array}$ & Eoriloh.- \\
\hline
\end{tabular}

\section{IQCALIZASION DR LAS OUSTABC IAT PECTICAS}

La sustancias péticas, solubles insolubles, se encuertran comoconstituyentes, en todos los tejldos de las planas, $y$ aún en maderas pero principalmente en los utos y rafces carrosas, desemeíando un importante papel durante el transcurso de la vida de los mlsmos In los estudios emprendidos para la localleación de las sustanclas pécticas y para determizar el estado y condicion on que ollas ea encuentran en el tejido celular, los distintos investigadores han re recurrido principalmente a los slguientes procidmientos: 
De coloración; quificos o de extracción e hlstológlcos.PROLRDIMIEITO DE COLORACION: LOs métodos de coloración se han ut111zado para determinar la distribución de las sustanclas pécticas on los tejldos,y además, por combinación con los procedimientos qui-. vicos, pueden revelarnos el estado on que ellas se encuentran on d1chos tejidos.-

Dentro de los distintos colorantes utilizados tiene importancla el ro jo de rutenlo irue (OH)2 0147 (NHB) 3420 que fué empleado por Katguir675) para la locallzación de las sustanclas pécticas y cưa tecnica es 12 sigulente:

Los cortes de tejidas son lavados con $H 20$ e inmediatamente son coloreados con una solución al $0,2 \%$ de rojo de rutenio, recientemente preparada.El exceso de colorante el que se ha depositado on las porciones no pecticas, es eliminado por sucesivos lavados con callente,pudlendo procederse despues a tratar las partes coloreadás con lo:s distintos reactizos quimicos.-

Manzuint: (75) utizizo este método para deteralnar la constitución de

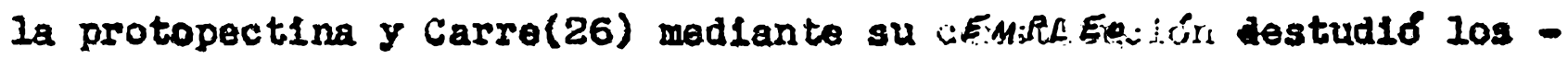
camblos que experimertan las ustancias pécticas de manzanas durante el proceso de maduración en camaras frigorlficos.Paublen este procodiniento ha sldo ut1lizado para determinar la presencla de clertos $\mathrm{g}$ upos funclonales ar la molécula de las sustanclas pécticas,asf schnelder (III) comparando la distinta afinitad que presentan la nitropectina y la nitrocelulosa frente a los colorantés báblcos,comprobó la presenel: de los grupos polares acidos en la nFtropectina.-

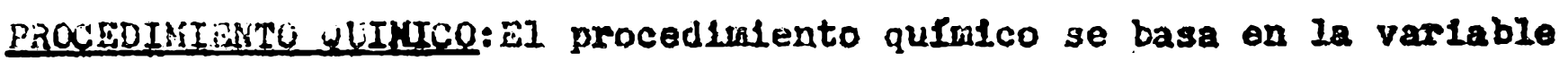
estabilidad quio presentan las sustanclas pecticas frente a 103 reactivos particilares que se utillzan para su extraceión y en el posterior examen de los productos obtenidos.-

Este p ocedimiento se ha utilisado para deterifilar el estado on que se enouentran las sistancias pécticas on los tejldos celulares, pero debe tenerse en cuenta que el examen de los productos de extracción puede proporclonarnostconclusiones erróneas, ia que durante dicho pro ceso la sustancia pectica original pucde surrir modifaciones o alteraciones en su constituclón.- 
Norman(87) sug1rió el slguiente procedialento para determinar el estado en que se encuentran las slistancias pécticas en lostejldos mediante el empleo de los agentes de extracción:

A) Extracción con HEO -..-Pectina libre

B) " "solución de ac1do oxál1co al 0.56--a-pectina 11bre y pectina combina con lones metálicos.-

c) Extracción con solución de oxalato de 1044 al 05\% - Pcctina lin bre o cominada y acido libre o combinado.-

De acuerdo a los resultados obtenidos mediante el empleo de 10 procedinientos anterloriente enunclados, parecerla que las sustanclas fécticas se encuentran preferentemento localizadas con das lugares de los tefidos celulares:Pared celular y laminilia intermediarla.-

la sustancia péctica que se encuentra en la pared celular serla protopectina (75), la cual durante el proceso de mitosis,serla derribada,formándose luego la pared deflnitiva por sucesivas adictones de capas de cluiosa, en la cual queden las slatencias pecticas en forma de incrustaciories.-

Eis cambio, la sustancla péctica constitugente de la laminilla intermediaria,queactuá como material de unión entre lascélulas,serfa de distinta naturaleza de la protopectina y se la considera ser un compuesto del acido pfetico, probablemento contiox combinado con el ca.(75), suposictón eśtaque ha sido nogada por Branfoot( 20).' sin embargo, esta diferenclación entre las sustancias pecticas cons titurentes de la pared celuiar y la laminilla intermediaria ha sido aceptada por Carre y Haynes (24-25) debldo a qle la sustanotert péctica en la laminilla intermediarla contine una proporción monor de grupos metoxilos que Ia sustancla pectica de la pared celular. SUSTARIIAS PUCTICAS DE LA PARED CELULAR:

Ia primera observación de la existencla de compuestas pécticos insolubles en los tejidos celularés fué hecha por Fremy (53) on su estudio histológlco sobre grosellas verdés.Mas tarde Nanzuln (75), por modio del procedintento de coloractón, confirab la presercia de los compuestos pét1cos insoilubles y demostrơ la inticia asociación de estos complestos insolubles con la celulosa,y que estas sustanclas no son modfficadas por los proco- 
de Iignificación ni de suberización.-

De la existercla de estos compuestos pécticos Lisolubles y por ancontrarse on intina asociación con la celulosa en la pared celular nace la controversia entre los distintos autores, 3obre la posible constltución de la protopectina.-

Sin embargo Tutin (123)nlega la existencla de la protopectina en los tejidos de frutas verdes y atribuyó la aparente insolubilidad de estas sustanacias péctios a la daricierte desintegración de los tejidos 10 chal dirlculta la extracción de los mismos.Más tarde,carré (24) en su estudio sobre tefldo de manzama por los procedilientos quinico e hlstológlco,demostró la existencia real de la protopectina, la cual por hidrólisis genera pectina.-

tDe esta controversla han surgido dos teorfas que pretenden expllcar la constitución de la protopectina;1) Uniones con la celulosa, ya sea, for conbinación con ella o por formación de un complejo y 22) Por Follmer1zac1ón.-

ntre los autores que sostienen que la protopoctira os une-ompuesto de pectina $j$ colulosa, tenemos a Von Fellenberg (50) quilin siug1rió que la comblnación se efectra por medio de un grupo carboxilo y la celuloj 3 , con eliminación do HeO.-

Carré(24) apina que la protopectina es un compuesto de pectina $y$ celulosa, on ol cual, un nímero variable de grupos metoxilos de la pectina son reemplazados nos grupos celulosa.De acuardo al número de grupos Ifetoxilos que han sldo reemplazados, por celulosa, se obtendrán protopectina:s de estabilidad rariable frerte a losiagiontes de extracción.-

sucharifa(118) opina que la protopectina es un complob de pectina y celviosa. Sste autor tratijando con cásara de I1món,obtuvo un producto que creyb que era protopectina pura,despues de elfalnar previuzante los conpuestos péction solubles por ixtracción acuasa y la celulosa por solubilización eln el faactivo do schrelzor :Luego por hidrolisis de estar yotopect1na obtenfa, en las sucesivas extraccionesfvarlables cantidades de pectina y celulosq libres,y anazlzando ostos productos observó que a modita gie disminufa el contenldo de metorilo de la pectina aumertaba la cantided de sa 11berada.- 
Sin ombaxgo Horman suglere que la unión de la molécula de pectina co: Ia celurosa, para formar la protopectina,no ha sido suficlentomonte probada,y por otra parto, contra esta toorla de argumenta ia facllidad con que la protopectina es hidrollzaga a pectina, por soluclones muy diltidas, tales cono, Ias de acicio oxallco al $0.5 \%$ 4 C1. N/75,0xalato de NIf4 al 05\%,ete.Sugín la teorla do polimerizactón la protopectina serla un politis molto de la pectina, el cual se formaria por la combinación bébil. de la pectina con elertos lones metalicos.-Esta teorfa se basa en la observación de que la pectina en prosencla de poqueras cantidades de Pe. da un gel Insoluble on 120 que se comporta on Igual far que la protopectina rrento a las agentes de extracción, y esta presunción es corroborada por 3 i hecho de que numorosos investigadores han encontrado Fe. on las centzas de pect1:as (25-50-88-96) no conoclendose 31 aste $\mathrm{Fe}$. se encuertra cono una 1uprareza colo1dal,que no puede ser sliminada por diallsis $(46), 0$ el 61 se enenen tra nooklado con lia pectina:-

Nang1 (87) de acturdo a esta teorla,supone que ia protopectina est rla constitufda por la polinerlración del f́cido totramotilpectico y acido pectico parcialmente estor 1 icado, cujos grupos carboxlos. libres estarian unidos a lones metclicosp-poobablemente al Fe. 6 C.3.-

Para Ehrilch(45) protopectina de la ralz de ievrolacha consistirla de un complejo formado por la sal de ca. 6 is de la pecting arar bano,el cral se ancuentra eri comblnación con la pared celular.-

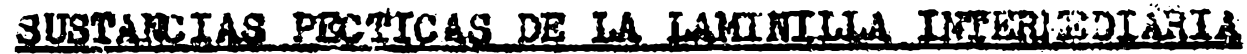

A las sustanc1as pécticas insoj.ables de lo laminilla intersediarita se las considera que son de distinta naturaloza de la protopoctina Asf carre y Haynes (21-25) designaban a las sugtanclas pécticas de la pared celular con al nombre de "pectosa" y a las stistanclas pécticas do la laninilla intorizediaria can ol nombre de "pectina" cebldo a su diforente couposicion quimica,jus esta dition contenti más celulosa y menos grtpos matoxllos, zulentras que la "pactosa" contenfa menos celulosa y was grinos metexilos.Mangire (75) sugtrif que esta sustarcia insoluble estarfa constitulda por pectato de Ca. 


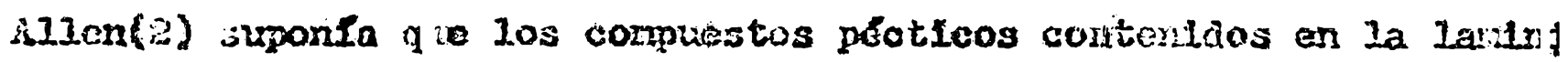
nilla interwediaria, orleinalwente estakan contitufios yor pectina natural, wero que duraite el. enfojeclalento deI tefla, exporiventan vouirlcaciones nás o menois laportantes en su contitición.Sica oplnión fue apoyada por Tupper-carey(124), on 3i estridio de la

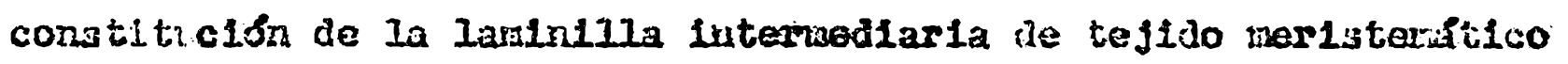
medlante el empleo je 103 grocedinjertos de exiracción y de coloraclón.-3itos artores observaron varlaciones an las peacciones de colaracion y una estabilldad variable frente a los agentes de extracclones, phes via parte de estas sustanclas eran fác1lmente hilpollza das por los reactivos comunes, tales como el axalato ie ral al $05 ;$

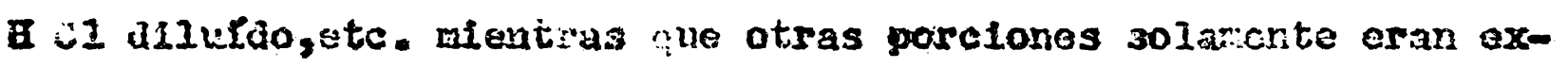
traldas despues de ser somotidas a un tratomiento irculo con peps!na,por 10 whal cedujeron qus estas stistanclas péticas ostabun cons t1turalas por un corplejo de protelna-petina.for otra parte, tamulon hi sto contirada la presencia de jusan clas nocticas on maderas por medio a estridos histolfelcos (6r) y de extracifín, aunque estos fittwos son difleliwente realizables deblío a que las sustancias pécticas se ercientran recnblertas por las capas de hemicelulosa, lignina, etc. especialoente en la laciliniIla intersediaria.-

Para la extracción de Jas sustanclas pecticas de maderas se han -

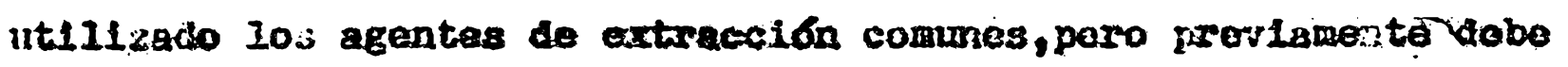
elininarse la hemicelinosa por medio de un tratamierito alcalino-

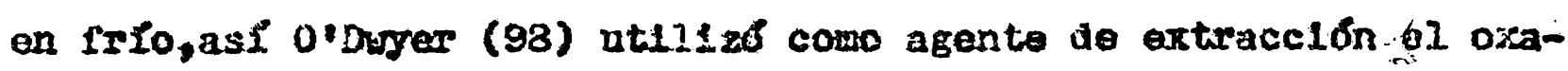

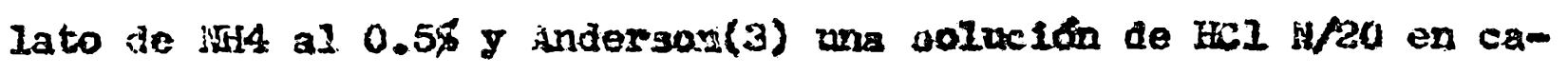

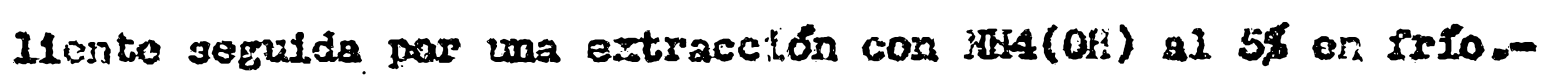
En toilos los tolidos celulares,adenas de las slistancias peticas -

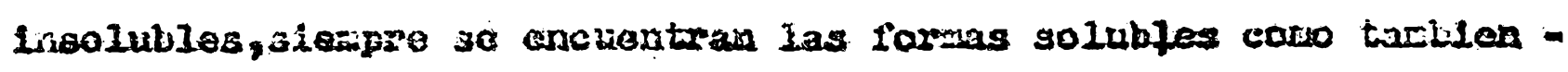
en is savia $y$ en 10.5 zxisos de trutas,

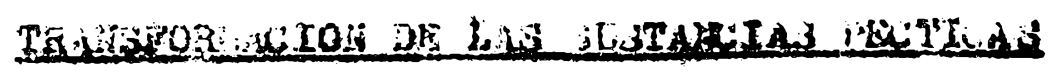
Las tranjformaclones que experimentan las sustanclas rafeticuas ha s1do atrifurda,desde los trabajos de prom (53), a la acción de las enzlrias, que son jegregadas nomalmente por los bejlidos o patolózta

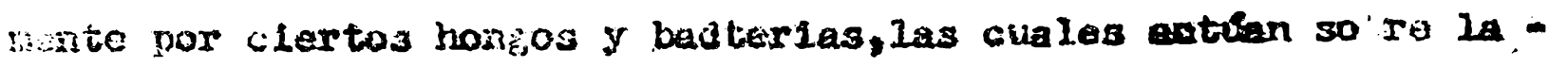
iroturectina, noctina $\mathrm{y}$ acki, pécicu. 
En la zetualidad, de acherdo al vomite de li joclodad julmica iroricana(89), se rcconocen tres enzlrias que actian soije las sistanclas péctlcas : Protopectinasa, Pectasa y iectosirasa.-

Las transforraclones que surren las sistancias pécticas jor 13 acción de estas enziras ha sldo explesto o: el capftulo de fomenclatura.-

La interconversion natu:al que experiachtan las justanclas pecticas han sito estudiadas por numerosos investi carré(23-25-26) quierr. realizo sus estudios en fratas .-iste autor ser̃aló que a medida que avanza el proceso ce maduración la proto pectina diswinuye eradualmente al par que ausuta la cantldad de pectina libre pudiendo 1 legar a formarse acidos pectinitos.ista transformeción de las sustanctas pactleas,heclat a expensas de ia Porma insoluble, cile se iradice por la fordita de la textura tel tej1do, va acompañada for un alelgazaziento de la pared ceilulur y da

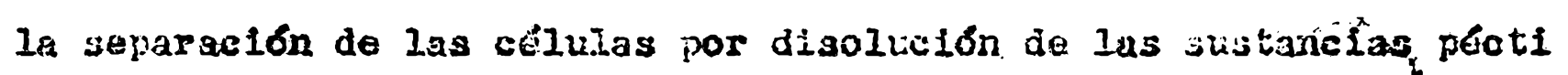

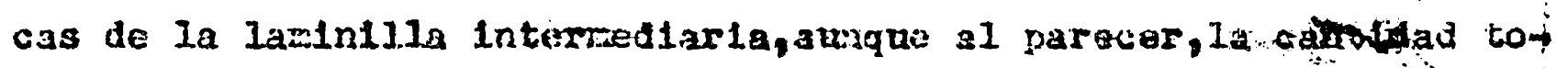
tal de las sustarcias fécticas, pertanece constante durante tado el yroceso.-

Las transformatones pato 2 i:icas que experirentan las sustancias noc ticas producidas por hongos y bactorias serian efectuadas por enztwas slmliarẹs, stno liéntleas, a aquellas segregadas normalmente por los teildos de la planta,y es probable cle estias secreclores prodicidas por tongos y bacterlas est6 constiturda por ura-rezcia cie veslas enztrias(20).-

Willarian (127), estidiando la acción del hongo selerotinea dinerea sobre tojido de ciruelas, observó que 1 a invasión del hongo al tej1do se producla nor la lisolición do la lavinizla lntersediara. bute autor observó que cuando el hongo sclerotinea cirera se dessrrolla en un zumo de frutas que contiane pectina, nodianto la enzlisa segregada,esta es floculada al estado de pectato de ia.-0trou autores oninan que esta acctón coactilu te deI La.no es espacifica (7-13-10)

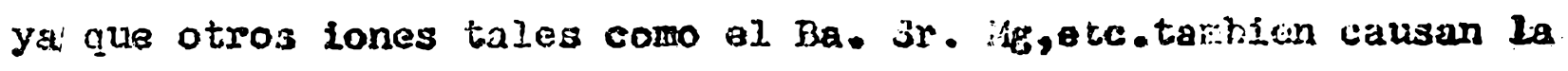
Hoculación del ácilo péctlca.-

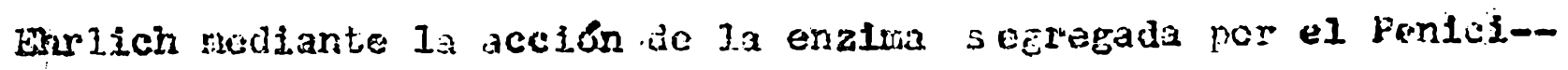

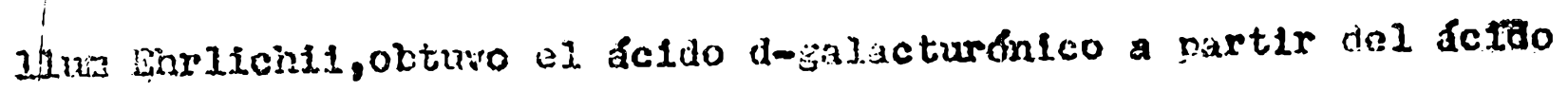


tetragalacturonico.-

Durante el proceso de enrlamlerto de la paja de lino,por acción de Ios microorganismos, la pectina sufre una degradación, y en parte es disuelta, lo cual es revelado por la disminución de su peso molecilar(15).-intre los microorgan1smos ue atacan a la pectina, durante el proceso de enriamiento, tenemos: $\mathrm{Bl}$ Granulobacter pectinovorum, el Felsineus anaeroblco $y$ otros que atacan a la poctina y a la celulo3a,tales como el lonilia sltophita $y$ en mucho mayor grado por el Alternaria tennis.

Felser (52b) observo que las pectinas a y $B$ conterildas en el tallo dej. 11no,prasentan distinto comportamiento durante el proceso de enriamiento pues la forma A.es comple:tanente llberada mientras que la otra ex no es elimirada por este proceso.-

Esta acción de las enzimas sobre las sustancias péticas ha sidoutilizada Industrialrente para clarificar y aumentar ze velocidad de filtración de los zumos de frutas(68).En siatesis, de acuerdo a willaman (127) 103 camblos que experimentan las sustanclas pécticas, puede ser representado on la sicutente forma:

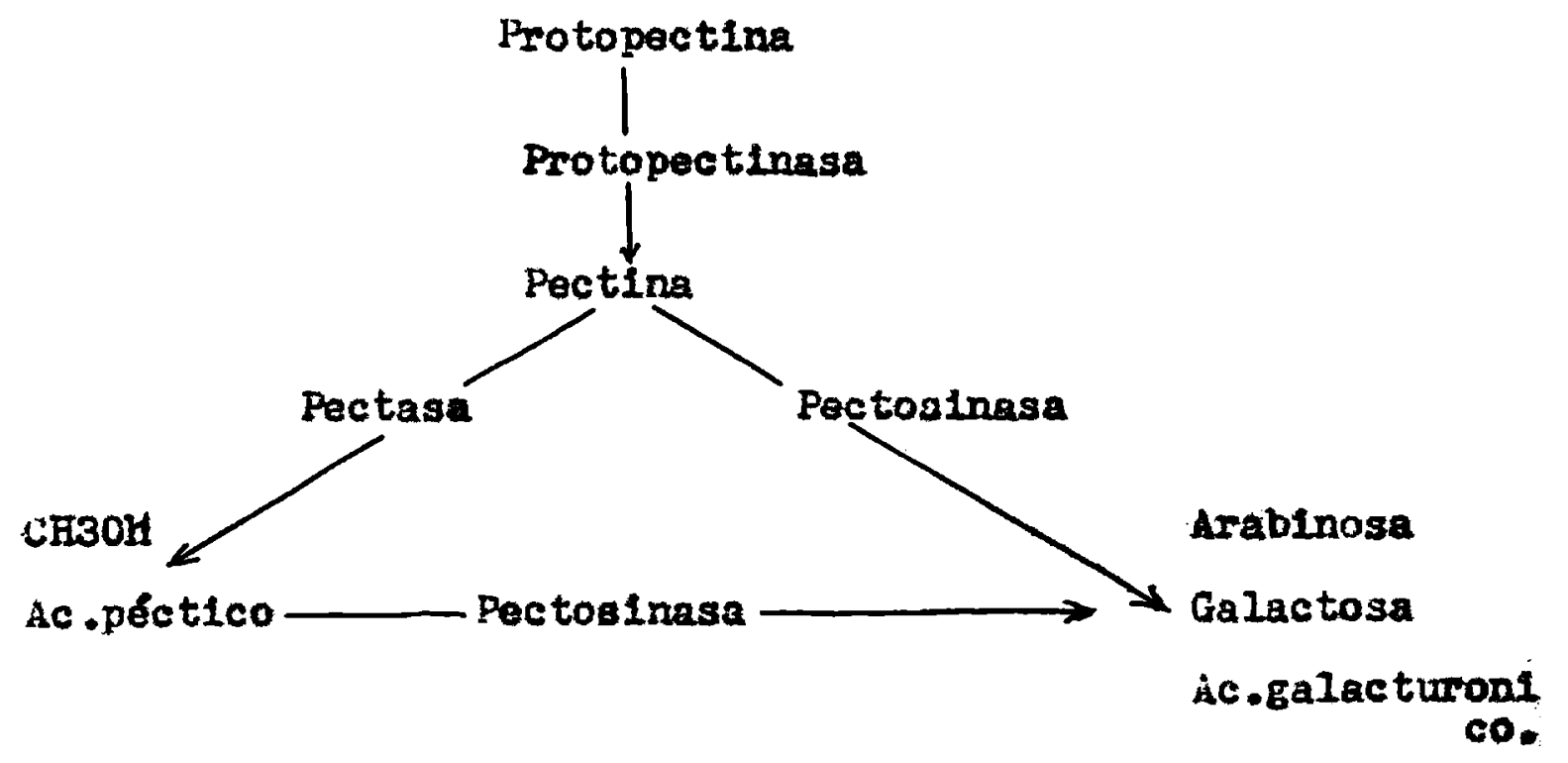




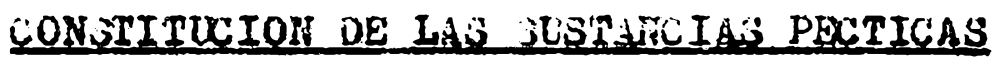

Dosdo los primeros trabajos efectuados para determinar la constitu-ción quimica de las sustancias pécticas,estan fueron inclufdas en el grupo de los hidratos de carbono, siendo relaclonadas por algunos investigadores debido a sus propledades ácidas con las sustancias mucilaglnosas,mientras que otros las relaclonaban con las gomas, pero real mente la identificación de las unidades constituyentes de estas sustancias se ha realizado a princlpio de este siglo.-

Bntre las unidades constituyentes de las sustancias pécticas, los pri meros investigadores pretendieron haber identificado varios azlicares. tales cono la arabinosa,galactosa, ílucosas, etc.-

Asf Helsberg deducfa la presencla de un azrícar on la molécula dé pectina obterida de la remolacha porque hidrolizandola con s04H2, produclafurfursidehtdo.-

Más tarde, Herzfeld(64l oplnó que la rectina estabe constitufda por un complejo de arabano y galactano, ga que la pectina por oxidación con s03H producla beido múicico.-

Tromp de haas (121) debido a las propledades ácldas de las shwtanc pécticas las relacionó con las sustanclas mucllaginosas y tambite Identificó la prosencia de arabinosa,galactosa y glucosa on lo ductos de h1drólisis de pectinas de distintos orlgenes,siendo rlormente confirmada la presencla de estos azúcares y en adic! losa cen los productos de hidrólisis de la pectina de naráts Baur(8).-

La presencla de glucosa en los productos de hidrólisis de I tanclas pectlcas no ha sido confirmada en los trabajos pos y en cuanto a la xilosa,su presencia on 1 a pectina de lin afirmaita por fhrlich (42), pero esto ha sido negado por of $(62-74-94)$.-

El perlodo noderno comenza realmento con los trabajos berg(49), quiten confirmó la presencla de arabinosa y za $\cdots-4$ intos orfgenes, $\mathrm{y}$ ademá-s descubrió la pr. - a de pectina,los cuales es' autor opino 
por el $\mathrm{CH}(\mathrm{OH})$, y calculó que la molécula completamente esterifleada contendrfa de 11 a $12 \%$ de metoxilo,ctrra que se encuentra en estrecha concordancia con 103 valores obtenidos experlientalmente por este autor.-

Además,comprobó que estos grupos metorilo eran completa y rápidamente ellminados por tratamiento con soluciones alcalmas diluidas $y$ en una proporción mucho menor por hidrólisis con joluclones ácidas. For medio de una hidrólisls acida controlada preparó pectina de naranja de contenido decreclente de grupos metorilo g que presentaban,por liberación de los gxupos carboxllos, ina acidez Geeciente.De los resultados de estos trabajos dedajo que las pectinas son esteres etrlicos del ácido péctico,siendo la pectina neutra, aquelia que tlene todos sus grupos carboxilos esterificados y es soluble on H20,mientras que las pectinas f́ldas son aquellas que tienen algun o algunos grupos carboxilos libres y que presenten un grado de solubilidad decreclente a medida que aumenta al numero de grupos earboxilos 11bres.-

En ese mismo ar̃o comlenzan los trabajos de Thrlich(37) quien estudiando los productos obtenidos por hidrosilsis de pectinas de ilmón y remolacha descubrió al ác1do d-galacturónico y CH3COOH y confirmó la presencla de galactosa y arablnosa,pudiendo esta última estar reenylazada por la metilpentosa y Ch30H bajo la forma de ester met! 11 co.-

Ehrlich consideró que la pectina es la sal Ca.Mg del ácldo arabino-galacto-metoxil-tetragalacturonico,al cual la arabinosa esta adhorida debilmente,pudiendo ser emilinada fác1lmente por hidrolisis áclda déb1l,obtenlendose el aaldo galacto-tetragalacturonlcá,ochplejo estable que requiere un tratamiento enérgico con solución als calina para poder eliminar del mismo a la galactosa.Más tarde, el mismo autor(45), esaudiando las sustancias pécticas, que orfinalmente se encuentran en la remodacha, distinguló las for mas solubles e insolubles,jlendo las primeras fáclimente extrafdas por un tratamiento acuoso a 60-80^c,mientras jue las segundas solamente eran extraidas por prolongado hervor con 1200 o por un tratami ento acuoso a presión.-

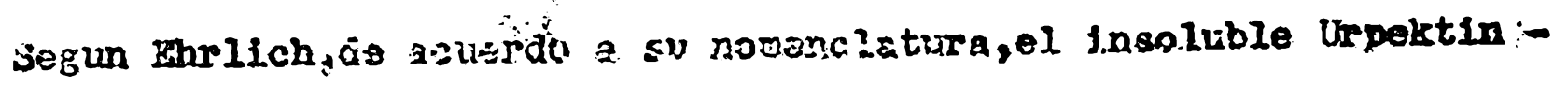


(protopectina) por prolongado hervor se transforma en el Hydratopektin soluble,el chal está constiturdo,por dos componentes que puedan ser separados,por sus distintas solubilidades en alcohol a 700 en callente,en : Tn 70-809\$ insoluble constitufdo por la sal ca.Mg. del pektifissare $y$ en un 20-30\% soluble constitufdo por un arabano levorotator10.-

por hidrólists controlada de la sal Ca.Mg del pektinsaure, por ellminación de arabinosa,galactosa,CH3COOHg y CH3OH, se obtiene el ácldo tetragalacturónico,que èstá constitufdo por 4 unldades de ác1do galacturónico que se condensan por ellminación de $H 20, y$ que puede presentarse bajo 3 modificaclones, $A-B-C$, con distinta rotación espocfflca,y cuya formula serfa la siguler:te:

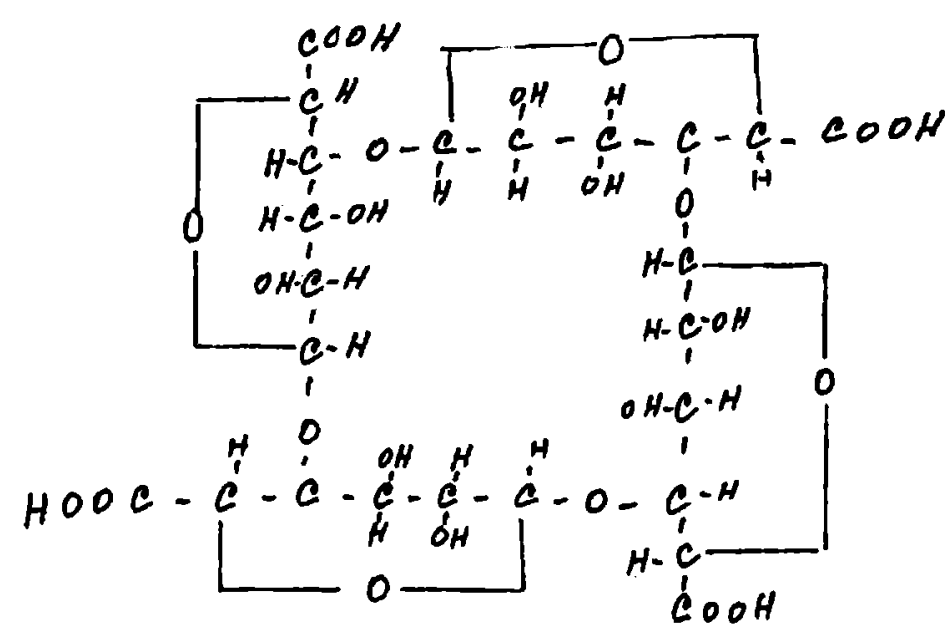

El ácido tetragalacturónico A[C20H28016 (COOH)14]presenta una $[x]+275^{\circ}$ el cual por adición de una molécula de 120 . se transforma en la forma $c$. designado por Fhrlich con el nombre de Paktol-

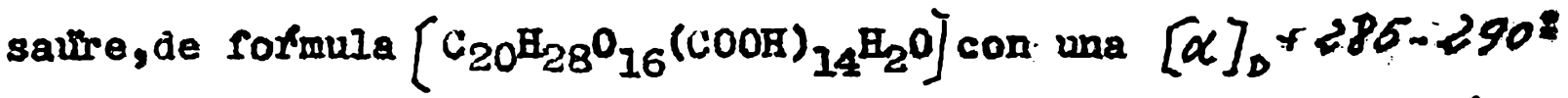
La iorma B.se producirla por la apertura del an1110, ya sea dè la forma A ó c,formbnciose una función lactona y que fué desingrida por Ehrlich con el nombre de Pektolactonsaüre de formula $\mathrm{C}_{20} \mathrm{EH}_{29^{\circ}} \mathrm{O}_{16}\left(\mathrm{Gg}_{\mathrm{g}}(\mathrm{coOH})_{3}\right.$ con una $[\alpha]_{D}+250^{\circ}$ Por una alterlor hidrólisis, con $\mathrm{SO}_{4} \mathrm{Bl}_{2}$ al $1 \%$ bajo presión o por acción enzimática,el ácido tetragalacturorico genera: el ácido d-galacturonico de formula $\left(\mathrm{C}_{6} \mathrm{~B}_{20} \mathrm{O}_{7}\right)$ que presenta an dos formas interconvertibles A. y B.con $[x]_{0}+97^{\circ} \mathrm{g}[x]_{0}+55^{3}$ respectivariente.Tambien las sustanclas púcticas orifinalme:te solubles presentan una degradación hidrolitica similar a las sustancias insolubles, per ro se diferenciande epfas en su composición qufmica,sogun 208 dato: sigulentes sumbistradus por Fur Iich.m 
Rewolacha

Naranja

Insolubles solubles Insolubles selubles

$\begin{array}{lcccc}\text { Ac.galacturónico } & 67.5 & 78,1 & 67.3 & 77,7 \\ \text { Galactosa } & 14,8 & 9,4 & 15,6 & 13,1 \\ \text { Arablnosa } & 13,3 & 11,3 & 14,2 & 10,6 \\ \mathrm{CH}_{3} \mathrm{OH} & 25,5 & 6,8 & 6,0 & 7,3 \\ \mathrm{CH}_{3}-\mathrm{OOH} & 10,4 & 8,5 & 10,9 & 12,1 \\ {[\alpha]_{D}} & +132,10 & +189,70 & +175,30 & +197,50 \\ \text { Peso molecular } & 1166 & 1006 & 1350 & 1303\end{array}$

Fn un trabajo posterior(38) de las tres modificaciones del ácldo tetragalacturónico,solamente persiscieron las formas B y C. pues ia forma a eué desechnda.-

El contenido de metoxilo de las sustanclas pécticas,segin lps datos experimentales de khrlich,oscllaba entre 5 y $7 \% .-$

La presencla del $\mathrm{CH}_{3} \mathrm{COOH}$ on las sustancias pécticas, on un porcentaJe de 10 a 12\%, fué descublerta por este autor on pectinas de diverso orígenes( $39-41-43-45)$ ì esto fué confirmado por Nelson(93) is wers (85)

an restimen, de acuerdo a los rabajos de Ehrlich la degradación de i la pectina puede ser representada en la siguiente forma:

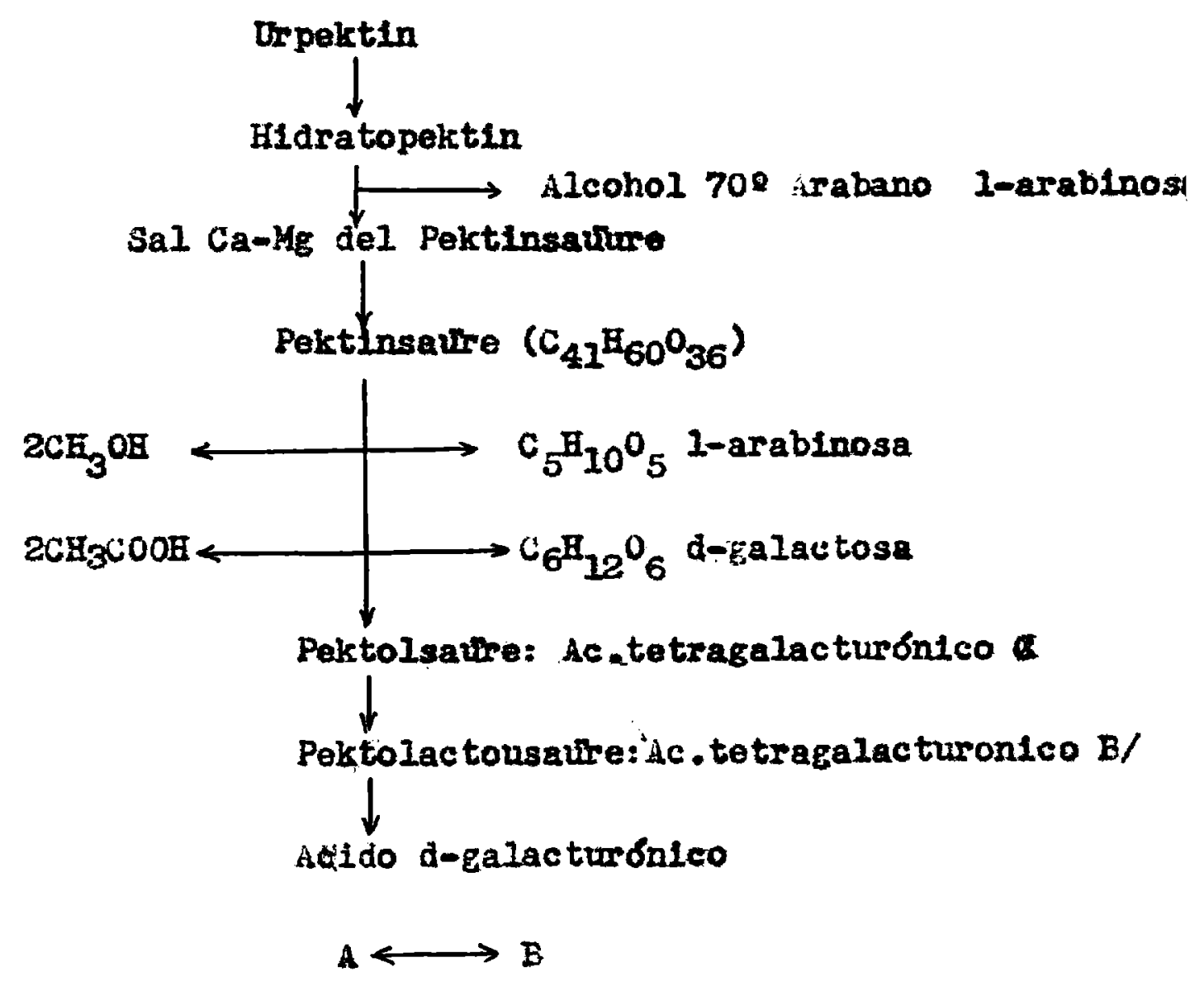

In suanto a la pectina dorlino, shrlich(42-45) dio las sigulente. 
cifras análfticas:

$\begin{array}{lc}\text { Acido galacturónico } & 61,6 \% \\ \text { Galactosa } & 14,3 \% \\ \text { Arabinosa } & 11,9 \% \\ \text { Xilosa } & 11,9 \% \\ \mathrm{CH}_{3} \mathrm{OH} & 5,1 \% \\ \mathrm{CH}_{8} \mathrm{COOH} & 9,52 \%\end{array}$

Bstudiando la pectina de la paja de lino,Henderson (62) la extrafa con solución de oxalato de $\mathrm{HE}_{4}$ al 05\%,la hidrollzaba con HaOH y por análisis del acido péctico resultante llegó a la conelusión que estaba const1tufdo por el f́c1do galactosa-tetragalacturón1co.de fórmula $\left(\mathrm{C}_{6} \mathrm{H}_{10} \mathrm{O}_{5}, \mathrm{HC}_{6} \mathrm{H}_{8} \mathrm{O}_{6}-\mathrm{H}_{2} \mathrm{O}\right) \mathrm{n}$ al cual por hidrólisis áclda genera un ádo pollgalacturónlco $\left(\mathrm{C}_{6} \mathrm{H}_{8} \mathrm{O}_{6}, \mathrm{H}_{2} \mathrm{O} / \mathrm{l}\right.$ semejante al deldo tetragalacturónico A de thrlich,pero que se diferencla de este por su mayor rotación especifica $[\alpha]_{D}=+3769$ \& atriburo los vestigios de arabinosa que encontro, en su anflisis, eran produclido's por la decarboxilación del áldo poligalacturónico.En camb1o Norris(94), de acuerdo a la cart1dad de rurfural-dehldo y ácldo noligalacturónico obtenldos,por análisis de la pectina de lino,1legó a la conclusión que esta responde a ka frrmula propuesta por fauj1 (83) pues estos valores concordaban estrechamente son los valores calenlados tebricamente on base a esta formula.Ludtke(74) opina que la pectina de lino extralda con oxalato de -

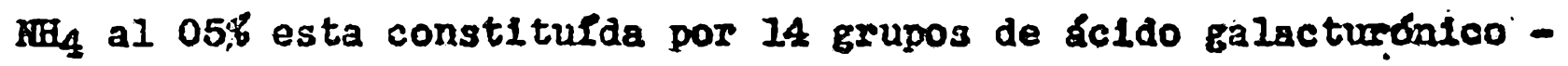
esterificados por grupos metrilcos, una unidad de arabinosa y una sustancia desconocida pero de distinta naturaleza de los nidratos de carbono.-

Tanto Este autor como Henderson y Norris no confirmaron la presencla de xilosa en los productos de hidrólisis de la pectina de lino. Scheyver y Haynes (122) prepararon ácidos pécticos de distintos ori genes y encontraron que todos. respondian a la fórmula $\left(\mathrm{C}_{17} \mathrm{H}_{24} \mathrm{o}_{16}\right)$ n Fellemberg (50) sug1r16 qua í molecula de pectina está constiturat por dos unidades de arabiñosa, una de metil pentosa, una de galactosa y 8 unldades de ácldo galacturónico esterlficado $\operatorname{con} \mathrm{CB}_{3} \mathrm{OH}, \mathrm{y}-$ cuya formula empirica zerla $\mathrm{C}_{78} \mathrm{H}_{120^{\circ}}{ }^{\circ}$-Este autor, en oposición a ihrlich,oplna que en ja molf́cula de pectina je mots.jpentosa esth 
slempre presente y que la arabinosa no se encrentra déblimente adherida al núcleo de la molócula.-

Ahmann(1) opinó que ol nícleo del ácido péctico está const1 tulaopor 10 menos,por sels unidades del ácido dibásico galacturónlco-galacturónico, 10 cual darla para a acido péctico un peso nolecular de 2124.-

Bowman(18)sugirió que el nucleo de la molécula de pectina de naranja está constituido por ol foldo arabinogalacturónlco, pero esta supo sición no ha sido confirmada, como tampoco aquella sugerida,por Ahmann, Nauj1 y otros(88), basándose en la producción de pectato de ca. y furfuraldehido, de pectinas de diversos origenes y preparadas por distintos métodos,suzirieron que el núcleo de la molécula de la pectina estarfa constituida por una unidad de ácido tetragalacturonico, uria de arabinosa y una de galactosa, respondiendo a la fórmula emplrica $\left(\mathrm{C}_{35^{\mathrm{H}}}{ }_{50} \mathrm{O}_{33}\right) \mathrm{n}$, la cuel concuerda con aquella propuesta por Schryver y Haynes,y que podrla ser representada en lar siguiente Sorma:

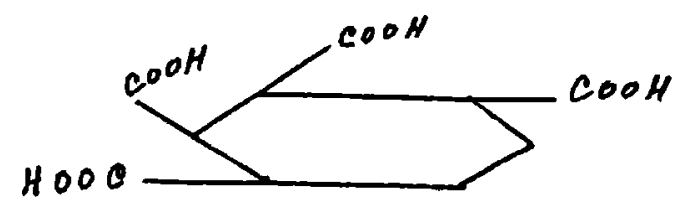

Ssta molf́cula,producirla $19,5 \%$ de furfuraldehido y contendrfa 69,7 \& de acido anhidrogalacturonico, 10 cual concuerda estrechamente con Ios valores obtenidos experimentalmerte por estos autores.ddemás estos autores no aceptan la presencla de la metilpentosa como constituyente del núcleo de la molécula de pectina.-

De acuerdo a esta formula el contenido teórico de metoxilo para el derivado tetrametoxilado sería de 31,768 y para el trimetilado $8.94 \%$.

Norris y 3cheyver (96) aceptaban la tormula de Naull y anallzandopectinas de distintos origenes encontraron que el conténido de motoxilo concordaba estrechamente con ol calculado para el derlvado trimetilado, por lo cual ettos autores sugirieron que en la pectina tres grupos carboxilos estafi detilados pudiendo el onarto,por ser Ilbre,entrar en comblnación para formar 3ales.Esita suposición fué conflrmada,sobre la base del contenido de metox110, por el análisjls de pectina de zumo de naranja(97) y de limon (91).- 
He Kinnis(76) oplna que el múcleo de la pectina de manzana no contlerie unidades de pentosa, ya que todo el furfuraldehido producldo provendría de las unidades del ácido pollgalacturónico.Nuers y Baker(85) sostlenen que el núcleo de la moléclila de pectina estarfa constituido por 8 unldades de ácido galacturónico que se consdensan por eliminación de 9 moléculas de $\mathrm{H}_{2}$ O.De acuerdo a los analisis practicados en pectina de naranja, 1legaron a la concluisión que ella está constitulda,slempre que no haya surrido una degradación durante el proceso de extracc16-n,por una Lnidad de galactosa, una de arabinosa,dos de $\mathrm{CH}_{3} \mathrm{COOH}, 31$ te de $\mathrm{CH}$ y 8 de ácldo galacturónico, las cuales se condensan, por eliminación de 20 molf́culas de $\mathrm{H}_{2} \mathrm{O}$, dando el ácldo arabino-galacto-diacetil heptametoxiloctogalacturonico con un peso molecular de $1866 \mathrm{y}$ que responde a la formula empirica $\mathrm{C}_{70^{\mathrm{H}}} \mathrm{O}_{98} \mathrm{O}_{58}$ Estos autores, sdemás, fieron los primeros en relacionar la integridad de la molécula de rectina con su capacidad para formar jaleas de pectina-azícar-ácido- $\mathrm{H}_{2} \mathrm{O}$.-

La suposición de que el núcleo de la molécula de pettlna está constitufdo por varlas unidades de ácido galacturónico fué confi inada por Iink y colaboradores(9-80-81) mediante el análisis dél Q a met11poligalacturónico-metil ester.-Para la obtención de este compuesto Link, extrafa la pectina cos solución áclda dilufda,neutralizada el extracto,hidrolizaba con fia.OH a $37^{\circ}$ y luego eliminaba las sales $y$ exceso de alcalf por sucesivos lavados con $\mathrm{H}_{2} \mathrm{O}$ acidiflcada con. HC1. -A este ácldo péctico lo trataba, on un condensador a rerlujo, duris rante 90 horas con $\mathrm{ClH}$ y $\mathrm{CH}_{3} \mathrm{OH}$ anhidro y obtenfa asl el $\times$ metil-dgalacturónico -metil ester y que contiena un $18 \%$ de metoxilo y: produce un $90 \%$ de $\mathrm{CO}_{2}$ :
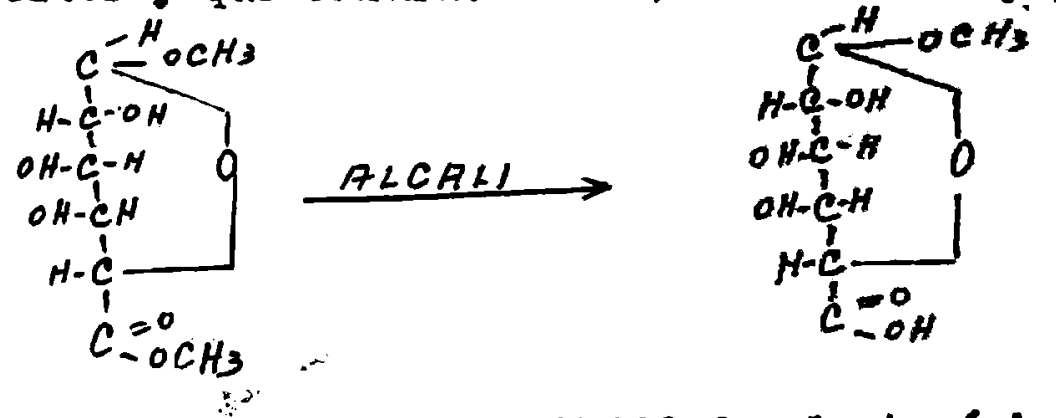

Met1l-d-galacturonico til ester Met1l-d-galacturónico Del metil d-galacturónico fetil ester,por acción de los alcalị,pueden zer separados los grupos metoxiloz quo se encuentran bajo la forma* de ester, no slendo afectados los grupos metaxilos que se eneuentran bajo la forma de unlones glucosidicas do cual parmite - 
cular el tamaño de la cadena molecular.-

Por comparación de 103 malores de metoxilo y $\mathrm{CO}_{2}$ obtenldas expe rlmentalnente con los valores calculados, tink llega a la conclu slón de queeste poligalacturónido contlene 8 unldades de ácldo galacturónlco unldos en cadena normal.-

vontenldo de metoxilo y $\mathrm{CO}_{2}$,determinado y calculado, de preparaciones de pollgalacturónldos, segun Llak:

\begin{tabular}{|c|c|c|c|c|}
\hline $\begin{array}{l}\text { Porcentaje de-- } \\
\text { terminado }\end{array}$ & $\begin{array}{l}\text { Metil } \\
\text { ester } \\
18\end{array}$ & $\begin{array}{l}\text { sal de } \\
\text { Na. } \\
1,40\end{array}$ & $\begin{array}{l}\text { Dri de } \\
\text { Ea. } \\
1,30\end{array}$ & $\begin{array}{l}\text { Producido on } \\
\mathrm{CO}_{2} \\
90\end{array}$ \\
\hline $\begin{array}{l}\text { Forcentaje gelcu- } \\
\text { lado para: } \\
8 \text { unidades de gal }\end{array}$ & & & & \\
\hline turónlāos- & 18 & 1,92 & 1,56 & 90,7 \\
\hline
\end{tabular}

De acuerdo a estas conclusiones la fórmula del $\alpha$ met1l-poligelacturónico metil ester seria la siguiente:

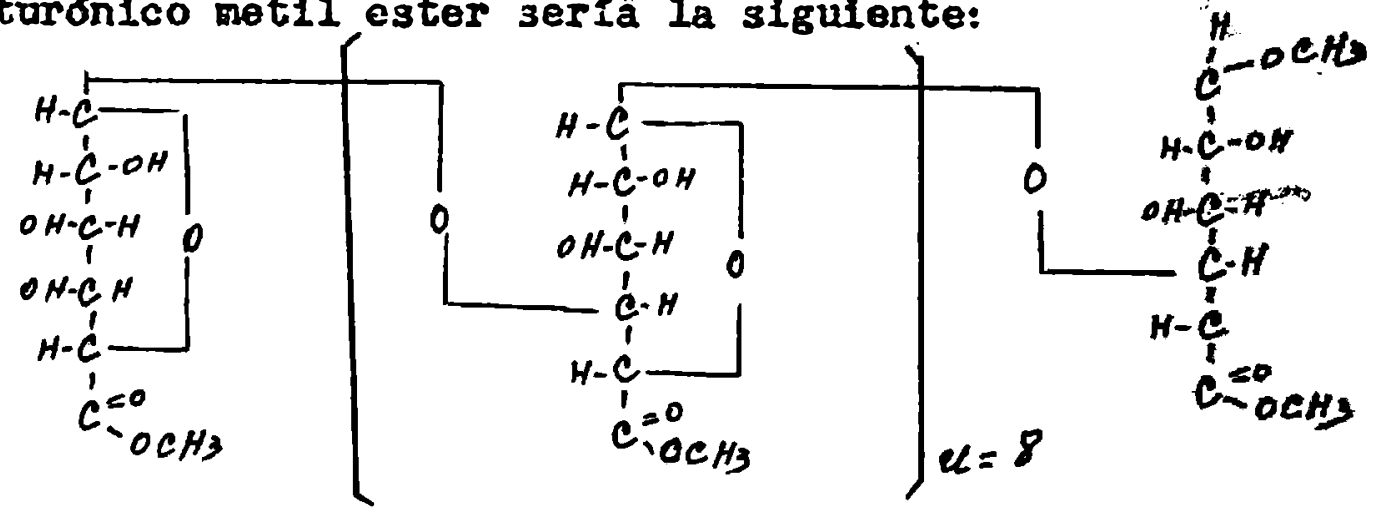

Meyer * Von Iterson (79b-125) mediante el empleo de rayos $x, 110-$ garon a la conelusión de que las unidades de ácldo galacturónico,en las sustancias pécticas, se encuentran unidas en fórma do cadena normal.-

Henglein (63) preparó pectina de remolacha por repetidas tracciones con $\mathrm{H}_{2} \mathrm{O}$ a obuliletion $\mathrm{y}$, despues de purificarla por sucesivas precipitaciones con alcohol, por nitración obturo el áclio dinttropéctico, irsoluble en $\mathrm{H}_{2} \mathrm{O}$ y solutio on las solventes or ántcos,y cuyas propledades filticas son simflares a las de la nitrocelulosa.-Por el método vicosiuétrico de 3kaudinger? aplicable solamente a sustanclas de cadena alargada,detormino el peso molechilar de este ester nftrico y encontro que oscilaba entre 20.000 y 50.000 dependiendo del netodo de preparación. Bonner (15) badándose en astoz trabajos propuso las sigulentes 
formulas para la pectina y el ácido péctico:

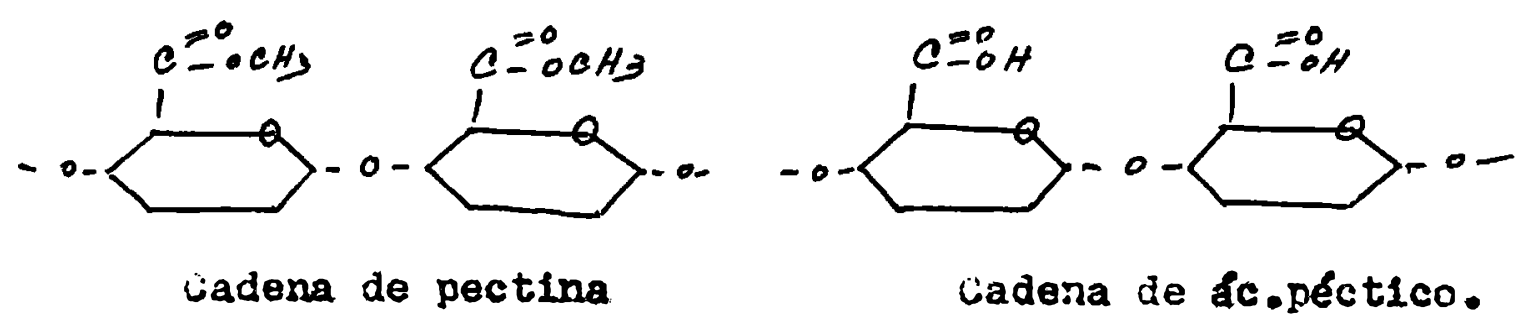

Aummás este autor ser̃aló que en el pectato de Ca. el lón Ca. actúa cono un agente de unión entre dos cad nas de acldo pétion mediante una atracción electrostática.-

Schnelder(111) deteruino,por bsmosis,el peso molecular de la acetil pectina y encontró que osellaba entre 20.000 y $100.000 .-$ ijte autor objervó que/la nitro y acetilcelulosa frente a los. colo. rantes ác1icos,pero en camblo rrente a los colorantes básicos, las p: primeras anfliestan una fuerte afinidad debldo a la presencia de. I0. grupos polares ácldos en su molécula.-

Jcaneider(107) por comparación de las medidas de bsmosis I viscosidad, cieñostró que la molécula de los esteres de pectina è àlargada paro de menor tamaño que la de la molécula de celulosa y en cliarto a su estructuragla pectina se asemeja más a la celulosa que al almidón. istos autores opinan que el pesc molecular de la pectina debe ser igial o mayor que el peso molecliar do los esteres de pectina,ya que dur ante el froceso de nitración,pueden sufrir alguna degradación.-

Schnelder(108) dewostró, sobre nitro pectinas, que los grupôs toxilo se encueatran como esteres metilicos porque medide que dis minuye su contenido se produce un aumento de ácidos y;aderás porque oxidando a la nitropectina con $\mathrm{NO}_{3} \mathrm{~B}$ se produce feldo múclco y no acldo met1l mucico.-Tambien demostraron que la arablnosa y galactosa no son constiturentes esenciales del esqueleto estructural do Ia nitropectija,y por lo tanto,del esqueleto de la pectina,y por otra parte,comprobó que la unión de las unidades del ácido galactarónico para formar la cadena no se reallza por medio de los grupos carbox1los(110), confirmando tsi la formuka propuesta por Bonner.Bock(15) efectio la determinación del peso molecular de distintas Dectinas $\mathrm{y}$ encontró que el poso de la pectina de frutas ascilaba entre 20.000 y 150.000 ; la pectina de la paja de lino de 11.000 a 16.000 y la de la paja d́e lino enriada de 3.000 a $10.000 .-$ 
jegun Bock (14) durante el proceso de enrlamiento de la paja de ilro una parte de la pectina es destrufda por los miconorganismos $y$ is pectina remanente no es atacada for una hidrólisis acida benigna.-

Felser ( 52 b1s) opina que el tallo de lismo contlene dos pectinas, A. y B. siendo la primera de valor comercial y que es lilberado du rante el proceso de enriamiento.- 


\section{EXTRACCIOA}

\section{PREARACION DE IA XUESTRA}

Con el objeto de obtener unamuestra en optir:as condiciones de ex tracciof, la materia prima debe ser convenientemente preparada.Para facilitar Ia completa extraccion de las angtanciar peetlcas Ja sea de las formas colubles o insolubles, la materia prima de be ser fingaent pulverizadn,pare la cunt ae ho recurrido dive aog procedimientos,que depender de la naturnleza de la materia pritin.-

Aol Carre (25) para extraer las sustancins pecticas solubles de aranzena, ríccutenda jesmonuzar la pulpa y ooseterla luego a la acción de una mezcla fricoriflca para producir la completa deain tegración del tejigo.-

iill1ams (129), en canbio, destruye la pulpa de sianzona por medio de un aprato triturador mecánico.-

Griees y iariy. (53-60) para extraer las austancl so peoticas de Ia cascara de limón, elintorn previanonte lo cortaza extrior amarilienta, gumergiendo infediatemente la parte blenca en alcbbol con al objeto de producir ou endureciziento y reducir el oscur-

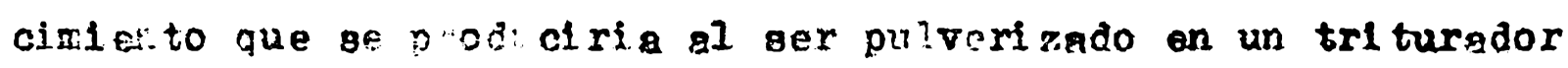
metál1 co.-

Luatice (74) recorlende tratar previemente al polvo de 1 Isto con C1:2 012 y luego on solucion de $I$ Cl allulio para obtener un mg yor rendiriento en In extraccion de las sustancins pectioas.For otra perte, Ia preparación de la muestra puede teder por objeto In elimingción de alcun constituyente de ln saterig pri-

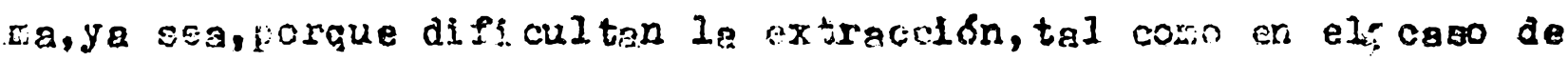

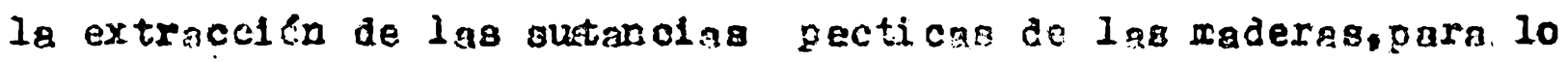
curl fué necesario extraer prevlarente la bericelulosa por mealo de soluciones alcalinas $(3-67-98)$ o tambien puede tener por obje to Is eilinincion de aquellos constituyentes que son extraldas conjuntarente con las austandas pectlcas y c uy: eliminación pog terior es Euchae veceo dificil de reellzar, tales como Ia redino aceltes, terpenos,etc.-

Se acuerdo a 30 recorendeso por Eourauelot g otron (17-52-i18) estos compuegtos organicos deben acr extraldos por oucenlron tra tarientos consolventes tales como c ? elcohol, otc.bajo un conden. sador a reflujo; esta operación debe realizarie lo mas rnpidam te cosible para evitar la hidroliala de la protopectina (50).Una ve: properada ln mue tra procedemos $a$ la extración de Ina sustoncias pectlcas.-

\section{exteccicon}

Ios procedimiertos de extrocelón de las anstanclas pecticas es tas condicioracias por el estado do solublildad o insolubilidad en eve dicha sustancios se encuentren on In musatroppwitiontras las priteras puejen ser extraidas por al mileo onlabiliza- 


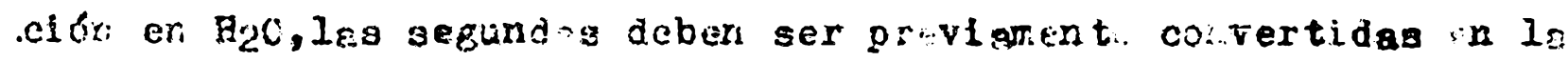
forre soluble.-

تrstas conversión de la protopectinn en pectira puede ser efectua da par cualquiera de los procerimi entos que a continuación ae melonan:

1) Por sucesivo tratamieriton con Hag a ebulilición \& tambien en autocleve a prosion.-

2: For tratrmlento con soluolones "goldas diluidas:-

3) For tratamionto con solucioneo de salea dilaldes.-

4) 20 acción de la protopectinas?.

5) For electrodialisis.-

Al se efectua Ia hidrollsis de In nrotopectins for prolong ido

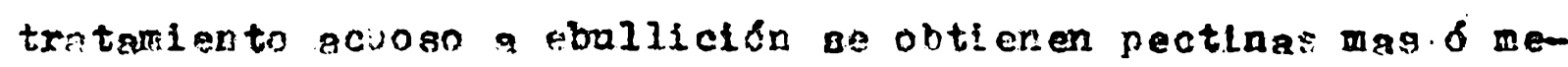
nos dereradades, con rapecto a su conterico te metoxilo,viscosidal j goder de falea,que degende de ln curación del tritami ento (55),mlentrag que las pectinas obterildes por tratamiento acrioso a presion pregerten ung cegrodacion gun mayor qlie se traduce por la completa perdida de au yoder celatinizante.-

Esta perdica de su po er Gelatinizante fue atribuldapor silgunoa invectigadore $(5 c-73-118)$, a la di inución del contenido de me toxilo, criterio ou an Ia actualldal no os compertido pro numeroso a inveatigadores $([-74-85-11 C) .-$

Il metodo de hidrolicis de $I_{a}$ protopectina mediante el expleo de soluciones ácides rilui as,o proceniriento Induatrlal ha al do utilizado por nirerosos lnvestigadores (57-53-55-58-60-85-87 etc) y presente la ventaja de que el contenido de metoxilo no

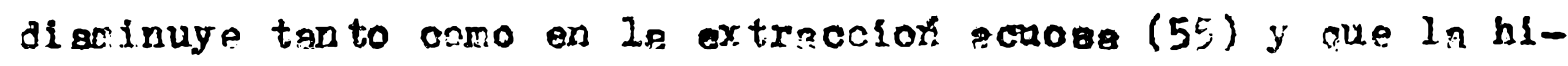
drolisis se efectua vás ropldamente oue medint el omple de soluclones de sales diluidas, tales coso le nolución de oxelnto $\mathrm{NF}_{4}$,perc a giz ver tiero el lnconveniente de ue por prolóngedo

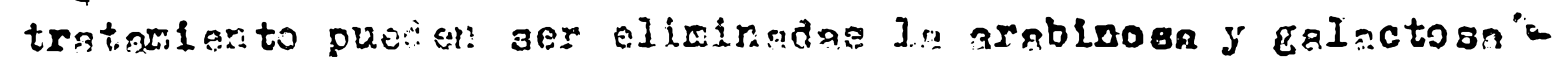
(37-85).-

La protopectinesa efeciua io hidrollais dx la protopectina - pectina,pero practicamente éste proculimiento ro ha sldo utiliza do, iers la obtención de pectina.-

Gortrer (57) obliere jecting soluble del deacto, de manzana,deg: pués de haber gi do obtenldo la aldra, sed ante un proceso de - electrods slisis.-

El buen exito qie se logra en lg extracción he pectlnageneroda

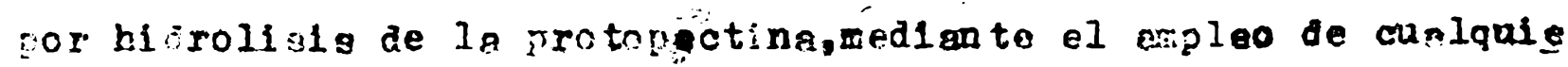
ro le los proceliniento gnteriormente enuacisdos depende de los sifuientes (actores: is) Yaterla prima;2) selado de diviain;32) Naturaleza de lo solución extractore; 4 ) concentroion de eata

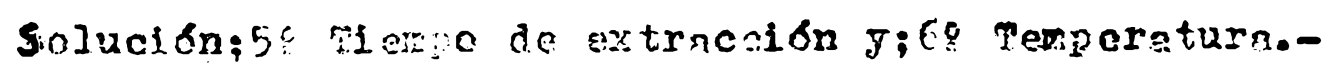


i su vez;estos factores condicionan: 1i) (arildad de pectina extraf CRLIDAD

da;26)(I1dad;38) Cantidad de furfurol $\mathbf{3} 48$ ) Cantidad de $\mathrm{CH}_{3} \mathrm{OH} .-$ Hardy(60) demostro que la cantidad de pectina generada,mediante una hidrolisis áclaa,varla directamente conez p.H. wa cuando la extracción se afectía a una tampsatira inforlor al punto de ebullición $\mathrm{g}$ directamente proporcional a la tomperatura cuando el:p.H. es menor de dos.-2ste alitor, por otra jarte,observó que il se sorrede la cascara de limón,a un proceso de extracción a presión y a un $p_{0} H_{0}=2$ la protopectina es complemamente destrurda.laker(36) fara thtoser una pectlua de alto grado de jalea,recomlen-

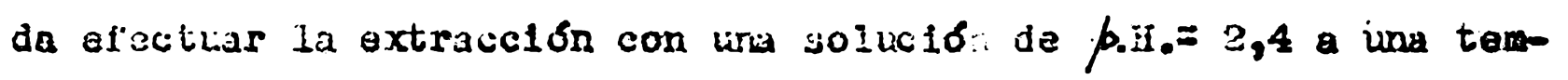

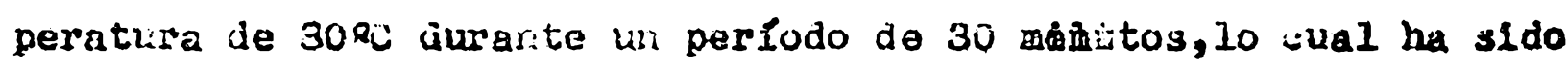
apoyado por Feliers ya que un periodo mayor prodixe una alsminucion deI podel" de jalea.-

Johustin(66) realizo extracciones de bectiva de citrus, por-tratamiencos acuoso y ácldo,a presión atrastérica y a alca presión y encontró que las pectinis oblenldas a alta temperatura presentan une disminufción do shi viscosidad y pojer do jalea.Ehrilch encontro varlaciones on el purcentaje de los constituyentes d Ia pectina, de manzanas, on funcion a lo temperatira de extraceion y cuyou análisis arrojaron las sigulentes cifras, segun thrlich $g$ jaense 1:

Temperatuia de extracción

$\begin{array}{llcc}200 & 600 & 800 & 1000 \\ 80,9 & 80,5 & 71,9 & 53,1 \\ 11,5 & 10,2 & 7,4 & 4,1 \\ 0,2 & \cdots & \cdots & -\infty \\ 55 & 5,4 & 10,1 & 15,0\end{array}$

aciao gulacturónico.

$\mathrm{CH}_{3} \mathrm{OH}$

$\mathrm{CH}_{3}$ ن OOOI

sisabinosa 5$$
5,2 \quad 10,1 \quad 15,0
$$

Johustin(5i3) racomienda para extrar pecilna do citrus at111zar,ce no egente axtractor, una solución 0.01 ri de il 18 a una tomporatura de 900 y yor cortos perlodos deus lo a que por apocto de la ebull1-

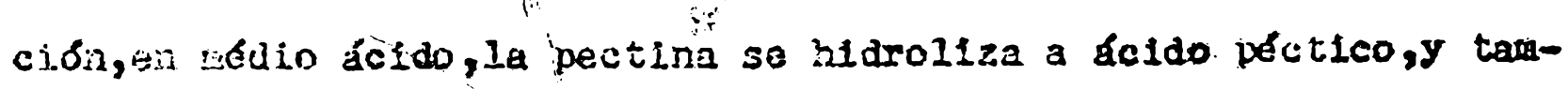
bien porgice un largo geilodo de calontamiento produce el alsmo oferto.- 


\section{PURIFICACIOA DE LOS BXTRACTOS DE GRCINAÖ.-}

AI efectuar la extracción de las sustanclas pécticas confunturente con ellas tanjlen son extraldas otras sustancias.-Ya sea en solución o en suspensión,que la impurifican,tales como restos de la materia prime,almián,sales,etc.y de cuya fluminación dependerá el grado de pureza de la pectina resultante.-

Goneralmente los extractos comerclales de pectina no zon objeto de una mayor purificación y combrmente este proceso se reduce a la 112 tración del extracto acioso, siendo luego concentrado a la conslation cla deseada.-

Para efectuar esta filtración se han : ropuesto distintas clases de generos como tamilen se ha recomendado flitrar el extracto a traves de kieselguhr(20) y cellte de grado analftico(129).-

Despues de efectuada la filtración del extracto se procedo a la ellInación de almidón y otras sustancias indeseables por média de la zcción enzimática (33) .0

Con el fln de obtener un p oducto más puriflcado se ha recurrido a la preclpitación de la pectina, coritenida en el extracto prevlamente flitrado,por diversos medios siendo los agentes precipitantes más utilizados al alcohol etillco,la acentona,sales de tales pesados, y tambien por un procedimiento electrolftico.-

Posiblemente, de estos procedimientos, el más utillzado es el basado en la acción deshldratante del alchol etilico que preclpita a la pectina en forma gelatinosa.-

Para efectuar la precipitación do la pectina por medio del alcohol etflico,Griggs(58) recomienda:DIIutr el axtract, hasta una concentración aprozimada al $3 x_{0}$ de pectine y agregar sobre el extracto,gota a gota,dos veces de volumen de alchol a 950,a temperatura ambiemte, $y$ mantenlendo la mezcla en continuo movimiento.Bn camblo otros autores (59-119) recomtendan la adición del extracto de pectina sobre el alcohol, lo cual tiene el inconveniente que produce la precipitación de lá pactine en forma compacta, por 10 cual quedan oclufdas en el seno de la misma,muchas impurezas.Esta precipitación de la pectina por medio del alcohol no se ofectía en forma cuantitativa,pues ella es parcialmentw soluble en alcohol a 802 y udemás tinie el frcurteniente de que la rectina pre 
cipita en forma gelatinosa sendo diffell de lavar y f1Itrar.Esta preclpitación de la pectina por medio del alchhol etrlico puede ser mejorada,cion el fin de obtener una precipltación clianti tativa $y$ en forma floculenta,por 19 adiclón de electrolitos (58126) O utillzando como agente preclpitante alcbhol acidificado (25-47).-Ambos procedimlentos tienen sis incorvenlentes: el primero, que incorpora sales que son absorbldas or la pectina y el segundo, que sl queda absorblda for la pectina suficlente cantidad de ácldo se trodrce una carbontzación del producto cvanto se lo somete a la desecación(229).-Fara efectuar ia precipitación de la pectina del extracto acuoso tamblen se ha utilizado la aceptona, que es una proporción del 50\% produce un precipltado floculento que es más fácll de flltrar que el obtenido mediante la acción del alcohol(129).-

La precipitación por medio del alcohol y la acetom tiene al inconveniente que además de la pectina tambien son precipitadas gomas,protelnas y algunas sales de va. y $X$ de ácidos organlcos (52-129).-

Tambien las pectinas, por ser cololdes negativamente cxgados, pueden ser separadas del extracto acuoso mediante un proceso de electrolisis,recogiendose el preclpltado floculento de pectina en el áriodo(58).-Esta precipltación puece ser acelergda por adiclón de alcohol etfilico al hidrosol, por cuanto este aumenta la polaridad(129 Este procedimiento tiene el inconveniente de que si el extraćto contlene una cantidad grande de electrolitos,la precipltación de la peitina, en $\theta 1$ anodo, no se produce(129).-Mediante el empleo de $\dot{s}$ sales metrilicas, tales cono sales de Al, $\mathrm{Pb}, \mathrm{Pe}$.etc.puede ser floculada la pectina del extracto acuoso.-

De estas sales, quizas las más utilizadas, como agentes preclpitante: son las de Al y Pb.-xsl Daker(6) recomlenda utllizar unasolución concetrada de $\mathrm{CI}_{3} \mathrm{Al}$ parcialmente neutralizada $\operatorname{cor} \mathrm{NH}_{3}$ a un te 3,55 pero sin formación del $\mathrm{Al}(\mathrm{OK})_{3}$ cololdal.wilson(130) precipita la pectina de limón con $\left(3_{4}\right)_{3} \mathrm{Al}_{2}$ y $\mathrm{NH}_{3}$, 1uogo la seca, y por último elimina el al por suceslvas lavadas con alcohol acidificado.Grigg3(53) utiziza cowo agente srecipitanso de la poctina ura вo- 
$1 u_{c} 10 ́ n$ de $\left(\mathrm{NO}_{3}\right)_{2} \mathrm{~PB} 0.01 \mathrm{Ne-}$

Ezta precipitación de la pectina mediante el empleo de sales no debe jer confurdidas con aquellas reacciones, en las cuale 3 la pectina es prevlamente hldrolizada,formandose luego una sal bajo la forma de pectato(61).-

Por cralquiera de estos procedimientos obtenemos ura petina prec1pltada, más o menos pura, y cuya ulterior puriflcación,generalmente, consiste en disolverla en $\mathrm{H}_{2} \mathrm{O}$ y repetir este proceso taṇtas veces cono sea necesario(5-53-63-118)

Bjia rectina asf purificada cortendr alin, lina varlable cantldad de cenlzas, que depende de la riqueza de sales de la materia pri ma,del método de extracción,y del grado de purlficación alcanzadc medlante el empleo de los procedimientos anteriormente enunclados AsI mett(46) extrae pectinas,de diferentes especles por diferentes ińtodos de extracción,y cliyo contenido de cenlzași àra el siguiente:

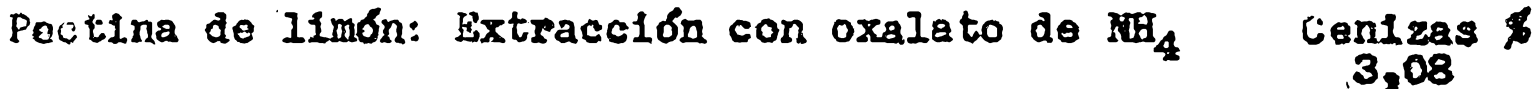

$\begin{array}{lll}" \text { " } & \text { con H Cl N/20 } & 3,57 \\ \text { Pectina de lapul:-a de liruón } & & 4,65 \\ \text { Pectina de manzara } & & 2,41 \\ \text { Pectina de zumo de manzana } & 5,46\end{array}$

Analizando las cerilzas de la poctina de la cáscara de limón se encontró Be.Al.Ca.Ha.K. y Cu. y en el caso de la centza do pectina de manzanas tanbien se estableció la presentia de Po. y cura existencia en cenizas de distintas pectinas ha sldo confirmado por zumerosos investigadores(25-50-83-96)..con el objeto de disminuir el contenido de cenlzas, se ha recomendado efectuar la precipltación de la pectina por medio del alcohol acidiflcado, to ctal produciría la solublización de alginas sales minerales que se encuentran al estado insoluble.-Ast, Origgs (58) ha conseguido reducir ei contentdo de centzas a $0.69 \%$ median te tres precipitaclones ácidas.-

Tatibien los electrolltos pueden ser elluinados, de las solweiones de pectinas,por tiedio del empleo de las resinas de cambio de lonad (129)

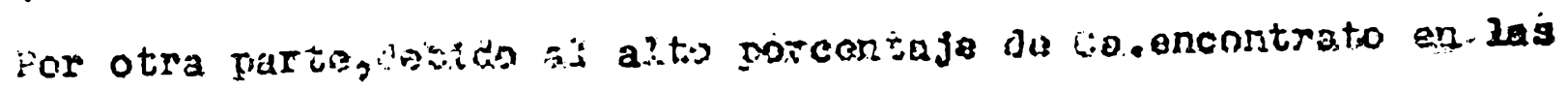


cenizas, se ha 1ntertado eliminarlo al estajo de ozelato de Ca.ya sea por efectuar la extracción con acido oxalico u oxala to de $\mathrm{Nth}_{1}$ o tamblen por adicióni de cxalatos solubles al extracto de pecilina, arites de epectuar la filtración del mismo.Fero el método aís cícaz para la clivinación de laz sales,contenidas en el oxtracto de pectira,es for aláiluls y, mejor aún,por clectrodiali:is.-

Grlggs(58) recomienda orectiar la diálists, con nembrana de pergaFino, de una solición de fectina aciaifeada con HCil N.001 hasta -

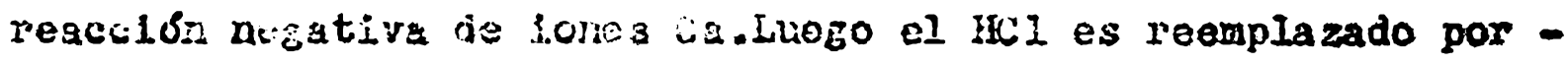
$\mathrm{H}_{2} \mathrm{O}$ destilada y $3 \theta$ conilifia el pruceso de diźlisis a no reacción de cloruros.for esto irtedo,el autor, sa conseguldo reducis el contonido de conizas do 2.650 a $018 \%$.-

Ssto procedinnierto tierce el inconvenlente de nue cada 4 horas la soluctón de pectina debe ser calentada a 9ax. para prevenir Ia accion bacterlana y además el, prolorzado tionpo que requiere ya que la reducción cltada ariteriomente se logra ciespues de dos semanas de dirilistis.-

Enmett(40) rezlizo un ostudio comparatioo para determinar el grado de eliminación de ias sales lrorgánicas que se logra mediante el empleo de los procedimientos du alálisis y alectrodialisla-

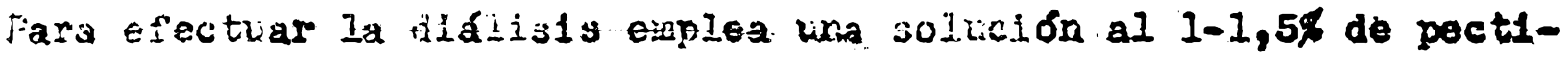
na,a la chal la cutre con wa capa de tolueno y CEid $\mathrm{C}_{3}$ para prevon1r la accióai bacterianá.-

In la electrodiallsis vtiliza un anodo de Pt g aplica al sistema ind cotrierite cuntinlia de 220101ts y 0.25 auperes.-Durante este proceso debe evitarse e calentanlento que so produce nor efecto de 1 in Interisidad de la corrlente.-

A continliación se transcriben los resultados obtenidos por este al. tor mediante el eúpleo de estos dos procecilulentos, en funclón del tiempo:

\begin{tabular}{|c|c|c|c|}
\hline & & Difl1sis & slectrodlélisis \\
\hline Porcentaje & Inlolal de conizas & 3,2 & 3,1 \\
\hline Despues de & 3 dlas & $-\cdots$ & 0,5 \\
\hline$"$ & 1 sevana & 0.74 & $\cdots$ \\
\hline$"$ & $4 n$ & 0.56 & $\cdots$ \\
\hline
\end{tabular}


Esta solución de pectina purificada ycasl exerita de sales puede ser comercializada bajo la forma de extracto,preda concentra-clón,o a partir de ella puede obtenerse la pectina en forma depolvo mediante el empleo de los procedimlentos de desecación.-

\section{DESPCACIOH}

Para la desecación de la pectina, los autores, han propuesto diversos procedimlentos.-

AsL Baker y Griggs(5-58) recomlendan efectuar la desecactión an estura a una temperatura no superior a $60 \alpha$. Leo $y$ otros(72) pa ra obtener la pectina desecada en rorma de polvo, utilizan un mátodo patentado basado en el procediutento ie desecación por medio del sistema spray o de pulverización.Emmett(46) rocomicnda deshidratar la pectina con alhohol a 950 Iuego con éter y finalmente terminar la desecación en un seca dor con $\mathrm{SO}_{4} \mathrm{H}_{2}$ al vacfo.-

Norris (97) propone efectuar la desecación de la pectina,previa mente deshidratada con alcohol de distintas gradnaciones y \&ter,en un secador con pentoxido de iósforo al vacio, previa ell minación del alcohol y eter por la acción de una corriente de alre.- 


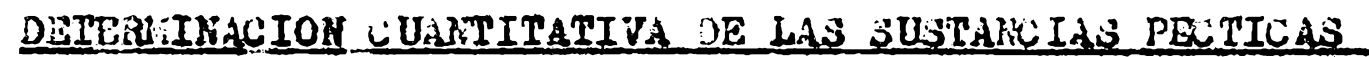

La determinación chantitativa diferenclal de las sustancias pecthcas,contenldas en una muestra, puede ser efectuada por medio del método fropuesto por Naujl y Norman(37) basado en la diferente solubilidad que presentan frente a los distintos agentes de ex tracción $y$ gue puede ser esquematizado en ia siguiente forma:

A)Extracción acuosa Pectina libre

B)Extracción con ácldo oxálico al 0,5\%——Pectina libre y co: combinada con lones Luetálicos.-

(i) Extracción con oxalato de $\mathrm{NH}_{4}$ al $05 \%$ __ Pectina libre y combinada y ac.pectico libre y com binado.-

$$
\begin{aligned}
A & =\text { Pectina libre } \\
B-B & =\text { Pectina combinada con lones metrilicos } \\
C-B & =\text { acido péctico,libre o combinado.- }
\end{aligned}
$$

La determinación cliartitativa del contenido de sustancias pécti cas de una solución ha sido encarada por las distintos investigadores,bajo dos apspectos:1) por precipitación de la"pectina y 28) Hediante ia deterninación de 103 productos gererados por hidróIIsis de la pectina.-

Para reallzar la precipitación de la pectina, contenida en una solución se ha recurrido generalmente, a la acción deshldratante dal alcbhol etplico (42-49-104-126) y ta:iblen al alcohol etflico ac1dificado (46-50-61), siendo Ilego lavada con sucesivas porciones de alcohol, secada y resada.-

Bil uso del alcohol etflico neutro tlene el inconveniente de que no efoctía una completa precipitación chando la concentración de la solución de pectina es menor de 0.04 a $0.06 \%$ (25) pues la pectina es parcialmente soluble en alcohol etrlico dilufdo y esto es. derostrado por la sigulente experlencia: 10ce. dei extracto de zumo de marizana fueron dilufdos cón cantidades creclentes de $\mathrm{g}_{2} \mathrm{O}$ y a cada dllución se le agregaron 50cc.de alcohol:

Cantidad de

$\mathrm{H}_{2} \mathrm{O}$ adicionada

$25 \mathrm{cc}$.
Peso precipltado

$\begin{array}{ll}I & \text { II } \\ 0,019 & 0.020\end{array}$




$$
\begin{aligned}
& 50 \mathrm{c.c} . \\
& \text { Vestiglos desplies } \\
& \text { do dos semanas } \\
& \text { No precipito ni atn duplicando la can- } \\
& \text { tidad de alcohol adicionado.- }
\end{aligned}
$$

Tambien este metodo biene el inconveniente de que por la acción del alcohol puoden precipltar algunas impurezas contenidas on la soluclón,tales como protelnas,gomas, etc.pr 10 cual los resultados obtenidos for este método son más altus quo loj dados por el método del pectato de Ca(47) como se puede apreciar por los sigilentes resultados:

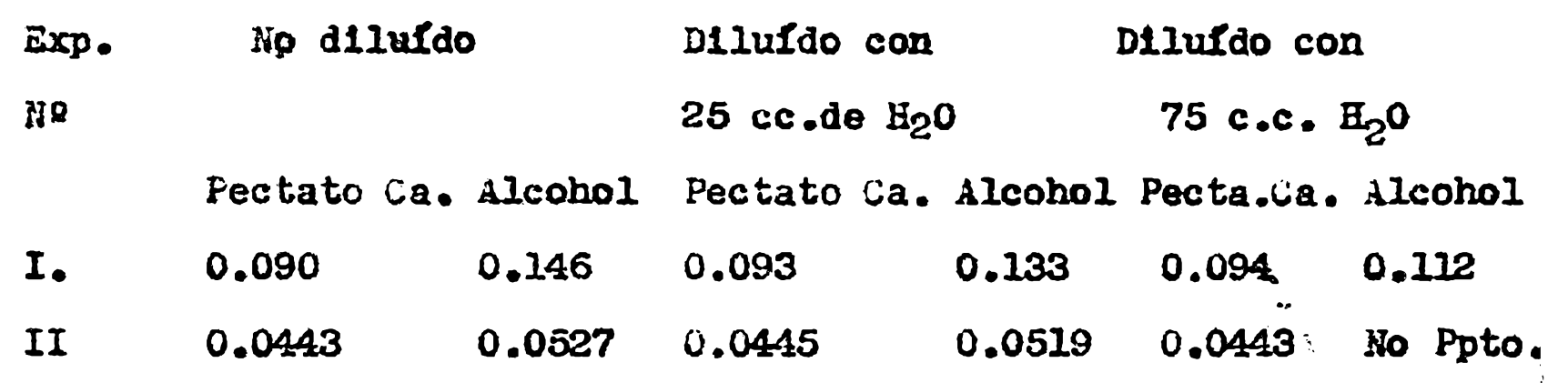

Wlckmann(126) diflere de estos autores,pues considera qito la pect1na aun en soluciones muy diluidas es insoluble en el alcohol etIl1co y que su rloculación puede ser lograda mediante la adición do -1 electrolitos.-

Pellenberg(50)recomendó utillzar alcohol acldificado para la deter-! winación de pectina,especialmente cuanto la solución contieno $3 a 103$ : de cia.-

Actualmente ha sido proplesto un aftodo para la determinacifn.cuant titativa de pequerias cantidades de pectina basado en un proceso of lectrol1tico (128).-isite método de determinaclón solo se puede utilizar para soluciones de pectina de bajo conterildo de electrolltos,pues il la concentración de electrolltos es alta no se produce el depósito de la pectina en 1 l ánodo.-

Para reducir la concetración de electrolitos de la solución de peotina, estes autores emplean las resinas de cambio de iones y,para. disminuir el tlempo de electrolisis recomiendan adiclonar a la $30-$ lución de pectina una cantidad suriclente de alconol etflico a 95 para obtener una cezcla con un tituio alcohólico de $40 \%$ en volumen Siste métodpe de resultados más altos quo los obtenidos adianto el método de immett-carré- 
Maranja Panzana Puelo

\begin{tabular}{llll}
\multicolumn{3}{c}{ Laranja } & Manzana \\
Eletro precipitación & 2,78 & 2,17 & 5,65 \\
Pectato de ca. & 2,57 & 1,99 & 5,16
\end{tabular}

Tazibien para detericinar cuantitativamento a las sustanclas pécticas se han : ropuesto métodos basados on el dosaje de los productos generados por hidrólisis de la pectina,siendo los más utilizados eimportantes los kasados en la determinación del ácido péctico y del pectato de ca.-

Asf Wlchmann(126) propone ol slgulente método para determina sectinas por evoluciṕn del ácido péctico.-

Rectúa una doble precipitación de las sustancias péticas con alcohol etflico,luego la solubiliza en $\mathrm{H}_{2} \mathrm{O}$ destilada, ehldrollza la pectina con uaa solución alealina dilufda, tras 10 clal,preciplta el ścldo póctico por acidificación con 1 il,separa frifración y lava a no reacción de ácido.-

Firalrente el precipitado es secado, pesado, Incinerado y vuelto a pesar.-

Este método tlene el inconvenlento,adenás de ser un procedimiento largo, die que pueden produclrse una solubil1zación del ácido pectleo durante el proceso de lavado a no reacción áclda.-

Tambler ha sido propuesto un mótodo de centrifugo(52) para la deter minación del ácldo péctico:la 3olución de pectina filtrada se coloca en tubos de centrlfuga raduados, se diluje con $\mathrm{H}_{2} \mathrm{O}$, se hidroliza con solución alcalina y luego se acldifica pard obtener el péctico.-Despues los tubos son colocados en baño marla para facili. tar la completa flocilación del ácido péctico,se dejan enfriar a temperatura amblente, Iuego se centrirugan 15 minutos a 2400-2500 r.p.m. e inmedlatamente se lee el volumen del precipltado obtenido. Ahmann(1) determina las sustanclas pécticas de la sigulente forma: 1 una solución con un contenido de 0.15 a $0.5 \%$ de pectina lo adic10. $n^{a}$ una solución alcalina de concentración conocida hasta que la concentración de alcall sea aproximada a $0.1 \%$. Se lleva la merela a in volumen determinado $y$ se deja estar a 55\% durante 12 horas percaneclendo el frasco her éticamente cerrado,para evitar la acción del $\mathrm{CO}_{2}$ atmosférico.-

Transcurricio este periodo se torian partes aliciotas g se titula el 
exceso de alcall con solución de Cl.

Del nimero de centruetros cúbicos de alcall comblnados, determina to mos la cantidad de pectina contenida en la solución; mediante el si. gulente czálculo:

Ha.(BH): Poctina:: Peso alcall : $\mathrm{X}$

$40 \quad 208.9$

Carré(25) determira las sustanclas pécticas al estado de pectato de ca.por el siguiente método:Toma una cantidad da la solución de pectina que produclrá de 0.02 a 0.03 gr.de pectato de ca.-a esta solución la lleva a un deterainado volumen por adición de $\mathrm{H}_{2} \mathrm{O}$ destilada,y le afiade,previa neutralización de la acidez,100 cć.de NaOH N/10,dejando la mezcla en reposo durante una noche-.

Iransuursido este lapso le agrega 50 cc.de ácldo acétlco $N$,dejando en reposo 5 minutos,adiciona 50 ec de $\mathrm{Cl}_{2} \mathrm{Ca} \mathrm{M}$, deja reposar 1 hora, leego se hlerve por 3 minutos, se filtra por papel y se fava el preclpitado con $\mathrm{H}_{2} \mathrm{O}$ destilada a $100 \mathrm{QC}$ hasta que el Ifquido de lavado no de reacción de cloruros.-El precipitado se transfière a un vaso, se suspende on $\mathrm{H}_{2} \mathrm{O}$ destiladas, se hlerve por 3 minutos 8 se vuelve a filtrar.- Sóire el liquido que filtea se investigan cloraros y en caso de reacción positiva debe repetirse esta operación hasta que el liquido filtrado no presente reacción de cloruros fren te al $\mathrm{NO}_{3} \mathrm{AB}$ -

Luego este precipitado es secado a $100 \% \mathrm{C}$ a poso constantê, 10 cual requlere un tiempo aproximado de 12 horas.-

Este método tiene el inconveniente de que no se puede efectuar la determinación de las sustanclas pécticas obtenldas por extracción con ácido oxalico u oxalato de $\mathrm{kfH}_{4}$ o de aquellas soluciones de pectina que contengan sustancias que con el ca. formen compuestos Insolubles on acido acético dilifdo.- Esta dificultad rue stibsanada por amett(47) mediante la siguie:te de la solución que contleno $0,2-9,03 \mathrm{gr}$. de pectina y efectía la precipitación de la misma con 4 reces su volúmon de alchol etrlied que contidre la cantidad necesarla de clf para produclr wa solu-; clón de $1 / 10$.-Deja en reposo una noche,filtra,10ego la:a al prec1pitado con sucesivas porciones de la solución alcohol-ácldo y finalbente la disuelve con $\mathrm{H}_{2} \mathrm{O}$ destilada callente.- 
Sobre esta solución acuosa de pectina, apllca el metodo sigerido par Carré(25').-

Durante el proceso de la procipitación de la pectina por medid dela mezcla alcohol ácica la concentracione de lones H debe ser elevada,pues de lo contrario la pectina no precipita cuantitativamente (47).-

Carvalho(27), para la doterwinación de las sustancias pectieas de naranje, vitilizo el siguiente mítodo: Efectua la extracción de las sustanclas pécticas por sucesivos agotamientos a obulifión con $\mathrm{H}_{2} \mathrm{O}$ adidulada con $0,4 \%$ de ácido cltrico,con duración de 1 hora por cada tratalento, reíne las extractos y los evapora.-De este extracto toma una alicuota que contenge alrededor de $0,4 \mathrm{gr}$.de pectina, di luye a un volumen ds $120 \mathrm{cc}$.neutral1za con $\mathrm{NaOH}$ al $10 \%$ y adiciona 200 c.c.de $\mathrm{HaOH} N / \mathrm{s}$ dejando en reposo 1 hora.Luego agregą80 c.c. de $\mathrm{CH}_{3} \mathrm{COOH} \mathrm{K}$,deja 5 miritos en reposs, adiclona gota a gota 50 c.c. de $\mathrm{Cl}_{2} \mathrm{Ca} .0,1 \mathrm{M}$,despues $100 \mathrm{c.c}$.de $\mathrm{Cl}_{2} \mathrm{Ca} 2 \mathrm{M}$ y calient a ebullición por 2 minutos.-Separa al precipltado por filtración, lo lava 4 vecos con $\mathrm{H}_{2} \mathrm{O}$ callente, luego 10 transfiere a un vaso de preclpltacion, 10 suspende en $\mathrm{E}_{2} \mathrm{O}$ destilada y 10 hlexve por 2 minutos.Wuevamete flitra, a traves de filtros taracos, y lava el precipitado a :O reacción de cloruros.-

Por ultio laya al precipltacio con alcohol a 95\%, luego con étor $y$ finaliente sea a 1002 durarito 5 horas.-

Ia determinación elantitativa de la pectina, efectuala por estos mótodos, se basa en que el pectato de ca. responde estrochamente a la

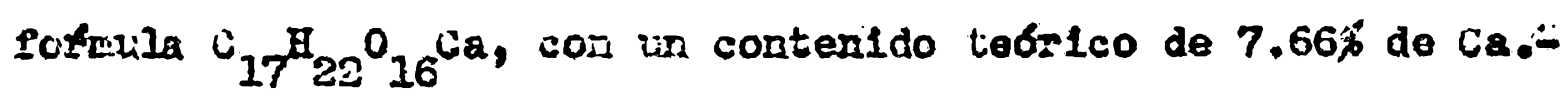
Además, se han propuesto métudos basados on el dosajo de la cantidad de $\mathrm{CH}_{3} \mathrm{OH}, 11$ berado por hidrúlisis, para la daterminación cuantitativa de la pectina.-

La cantidad do $\mathrm{CH}_{3}$ OH generado sue doterminada por Fellenberg(50) por el método de Zelzel-Denige, plentras que Marjl (37) 10 determino por axidación $\mathrm{CO}_{2}$ con solución alcallna do pímanganato,Tamblex, han sedo propuestos métodos, para la deteminación de estas sustanclas, basados on la cantldad de $\mathrm{CO}_{2}$,produclda por docarbaxilación en medio ác1do(30-35-71-88) y en medio alcailno (22) -Bstos métodos teenen el inconveriercte de que tambien otras sustanctas- 
35

den producis $\mathrm{CO}_{2}(92)$

- 


\section{ZROPIEPADES COLOIDALES}

La pectina por dispersión on $\mathrm{H}_{2} \mathrm{O}$ da in sol cololdal viscoso,opalescente a la laz reflejada y claro a la luz transmitida, en el cual pueden ser obeervados el efecto Firndal y los movimiertos Browlanos (58) \& curas particulas cololdales presentan una carga negat1va..

Este hidrosol puede ser transformado en gel por acción dez clertos lones metálizos,especlalmente por el $\mathrm{Pb}$ o por medio de un proceso electrolitico(129).-

In este hidrosol la pectina actía como un cololde protector ja que sl se le adictona $\mathrm{CL}_{3} \mathrm{Pe}$ y HaOH no se aprecla la formación de$\mathrm{Fe}(\mathrm{OH})_{3}(50)$.-

El grado de dispersión, de un sol de pectina de manzana,fué deterninado mediante el empleo do membrenas filtrantes fracclozadoras(79) encontrándose que el 35 de las partfculas son de un tamafio superlor a $0,6 \ell$ el $60 \%$ oscila eatre 0,2 a $0.6 \mathrm{~g}$ el $10 \%$ restante son menores a $0,2 u$.

Los soltes de pectinn presentan, a 1gualdad de concentraclón, una an-que los soles de gelating(58) y esta viscosidad yor viscodidadrelativa varia no solo en funclób del f.H.(27-83-) sino tamblen por ácido presente, ya que el áclo citrien dismtnure la visocisldad del sol(101-).-

Una de las propledades más sobresallentes que presentan los soles de pectina es la aptitud de formar geles,especialmente los const1titufdos por pectina-azícar-acido-agua, aunque tambien pieden ser obtenidos geles de pectina alcohol.-

Distintas teorlas han sido ealtidas para expllcar el papel que des empeña cade uno de los constitugentes on la formación del gel pectina,-azúcar-ácldo- $\mathrm{Z}_{2} \mathrm{O}$.-

Ios distintos actores coinciden en aflrmar que on la formación del gel la acción preponderante es desemperada por la pectina, la cual es favorecida por la acción deshicratante del axbicar, ilentras que el papel desempeñado por el ácldo es poco conocido, hablendoselo tr; bufdo clerta influencia sobre el grado de disparatón de la pectina. Las distintas teorfas emitidas que pretenden expllcar la formacion del eel, en base a la función desempeñala por la pectina,pueden ser agrupacas en:1) lor coagulación y 24) For formación do un compuestoj- 
Sucharipa(1118) oplna que la formación del gel se produce por la coagulación de la pectina,cuando se alcanza por evaporación,el limite de su solubilidad,quedando la pectina uniformemente distribuf da en la masa del gel en forma de mallas.-

Tarr(120)opina que tsta precipitación de la pectina, se produce deb1 do a la acción deshidratante del a zúcar y que además está infiuenclada por la concentración de lones H.-

In camblo Spencer(116) supone que la precipitación de lapectina es debida a la neutralización de su carga negativa por intermedio del azúcar.-

Griggs(58), en base a sus observaclones por medio de rayos $x$, y ultramicroscópicas, opina que los geles se forman por la precipitaclos de la pectina,-

Entre las teorlas que pretenden expllcar la formación estructural del zel por un proceso de comblnación, tonemos a la de Tarr $\nabla$ chernoff.-

El primero (119) suglrlo, basándose on el efecto buffer de la pect1. na,que el gel es formado por la combinación de la pectina con el ácido.-

Chernoff (28) opino que la combinación para formar el gel se produ. cla pntre los grupos alcohblicos del azricar y los carboxilos libres de la pectina.-

Estas teorlas de la formación de un compuesto químico durante el proceso de gelatinización han sido refutadas por los siguientes autores.-

Sucharipa( 118) consigulf eliminar dol gel, mediante lavados con alcohol a 750, la casl totalldad del ácldo y azticar y estos resultados fueron confirmados mediante $u$ proceso de dialisis(58) to cual indicarla que no se forma un compuesto quimico de la pectina ni con el écido ni con el azúcar.-.

La accion desemperada por er aci to ha sido estudiada en sales Y geles de pectina.-En los priperofisa variacion del fi $(27-58-83$ produce una variación de la viscosidad del sol,mientras que on los segundos, por varlación del f.H.se obtienen jaleas de distinte cal1dad (5-119) sobre los cuales actuaria como. un agente limitante(6) Actualmente Baker(6) opina que la estructura fundamental del gel 
asta formada por moléculas de pectina dispuestas en forma de malla - enrejado unidas entre s1 por uniones de carga con lones multivalentes.-

Anteriormerite se pensaba que el poder de jalea de una rectina esta. ba en relación directa con su contenido de metoxilo(50-118), criterlo que no es aceptado en la actualldad, Ia que los grupos metoxiIos,al igual que los lones monovalentes,no permiten la formación de untones de carga(6-74-85), - -ian la actualidad so plensa que la car Iidad de la pectina depende del grado de pollmerización del acido poligalacturónico(32-63-80-85-88-108-109-110-111) y que el grado de tilación,de este ácldo,determina la calldad de la jalea que se obtendrá(82-83-100-131).-

Los distintos autores para obtener geles de pectina-anfear-deido$\mathbb{B}_{2} 0$, han ut1lizado cantidades variables de estos constitujentes,pudfendo ser reemplazado alguno de ellos,parcial o totalmente,$y$ además han efectuado ol p oceso de gellficación bajo distintas condiciones experimentales.-

Asf, Sucharlpa(118) para óbtenar estos geles ompleaba usa concentración de $50 \%$ de azúzar, 1 de pectina y $0,5 \%$ de ácido cltrico.Hall1day(59) obtenfa geles con 50,8 de aztcar, 18 de ácldo ertrico y una cantidad de pectina que oscilaba entre 0,42 a $0.70 \%$. S1ngh(114) observó que se podfan obtener geles de contenildo varlable de azúcar,ompleando distintas concentraciones de pectina y ácido.- Este autor por aumento de la concentración de pectina consegula distninulr el porcentaje de azúcar.-

Cruess(32) observó que los geles preparados con zumos de erutas,contenlas de 65 a $70 \%$ de azúcar y una acidez de 0.5 a $1,5 \%$ valarado como ácido cltrico.-

vors(8?) determinó que la cantidad de ác1do que prode estar presente on un zumo de fruta depende de la acción buffer que ejerce dlcho zumo.-

Goldthwalte(56) comprove que el acldo tártrico es el quo padoduce las mejoras Jaleas.-

Tarr (119-120) deternino que la cantidad deazúcar cortenlia an un gel,permanecinntio snnstante la cantidad de pectina,no varla en - 
funclón de la acidez total, pero sl en función del $p$.ï. $y$ del b́c1do utilizado,per esta concentración del azúcar nurica es inferior a 64\%.-Este autor, empleando ácido citrico,tátrico y $\mathrm{SO}_{4} \mathrm{H}_{2}$ dio como $\$$ H optimos $3,3,3,2$ y 3,1 respectivamente; en camblo, otros autores,(73-78), recomiendan $k_{\text {.H. }}$ que osc1len entre 2,9 y 3,1.Johnstin(66) opina que la cantidad de pectina necesarla para produclr una buena jalea depende de su origen y de que no haja sufrido degradación durante el proceso de extracción.-

Por otra parte,la fuerza de jalea de una pectina altamente polimerizada y de bajo contenido de metoxilo,a un determinado f.H.es inrluenclada por la presencla de lones metálicos.Asf,Follenberg(50) comprobo que la adición de sales de feldos orgánicas a un sol de pectina-azucar favarece la formación del gel, nientras que la adición de salos ninerales causa la preclpitación de la pectina.-

Hers(82) opina que los aniones actuan como agentes buffers y pect t1zantes,81 estan en suflclente cantidad,y de este modo previeniem la JIN⿴囗isisis y aumentan la fuerza de la falea resultante.Halliday (59) preparó geles con ldde pectina,l is de acido y $50 \%$ de azicar y comprobo que por adición de ix de $\mathrm{CI}_{2} \mathrm{Ca}$ la proporción de estos constitiyentes puede ser reducida en $50 \%, 70 ; 0$ y $8 \%$ re respectivamente.-

Griggs(53) preparb geles de pectina-azricar-ácido- $\mathrm{H}_{2} 6$ on las cuales sustityo el $50 \%$ de la sacasosa por dextroza.Adems, otros autores, han obtenido geles anbstifujento todalmante alguno de los constiturentes.-

Asf Goldthalte(56) preparó geles sat1sfactortos empleando gllcexh na en vez de sacarosa.-

Baker(6) ut1lizando pectina de optima calldad obturo geles en los cuales el azúcar habla sldo sustlylifa por pequefias cantidades de lones multivalentes, tales como el ca.-

Tamblen se ha demostrado que la acción del calor no es nocesaria para la formación de estos zeles,ya que ha sluo posiblo preparar gelos de pectina-azúcar-ácido- ${ }_{2} 0$ sin ningun calentamtento(58).- 
PARTE PRALTICA

\section{CAPITULO II \\ NUESTRASE-SU ORIGEN}

Las distintas varledades de somillas de lino, utilizadas en el presente trabajo, han sido suministradas por el Ministerio de igricultura de la Nación,y provienen de la cosecha 1946-1947 efectuada on las Estaciones Experimentales que a continuación se detallan: Varledad Entre Rlos:Instituto F1totén1co Santa Catalina.Ilavallol

$$
\text { F.C.Sud.- }
$$

Varledad Benvenuto Labrador:irladero Santo Domingo.-Nonte Buey.-

$$
\text { F.C.C.A.A.- }
$$

Varledades Buck 3 y 114:Crladero Euck.-La Dulce.-F.C.J.--

Varledad la Previs16: 18: Estación Experimental La Presisión.-Ba-

$$
\text { srow.-F.C.Sud.- }
$$

Varledad Klein 1l:Ctladero Kleln.-Alfonso.F.C.C.A.

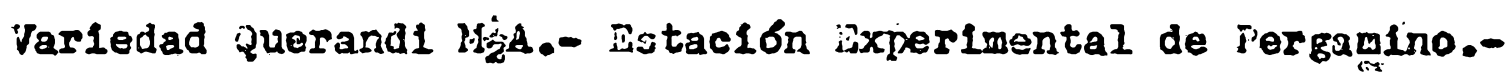

\section{PREPARACION DE LA MLETRAR.-}

como primera operación,con el objeto de facllitar la eliminación posterior del acelte, efectuamos una mollenda lo más fina posible de la semilla, mediante la acción de un molinillo.-

El mayor o menor grado de trituración alcanzado, por medio de esto aparato está condiclonado a que no se produzcan pérdidas de sulte por efecto de la presión y elevación de la temperatura,debida al roce,por cuanto está pérdida,nos darla luego un major porceritajo de pectina al relacionarla a la semilla total.-

De esta semilla mollda pesamos en un cucurucho de papel de flitro prevlamente desecado y tarado,exactamente $5 \mathrm{gr}$. I 10 colocamos era un aparato de Soxhlet, procedlendo luego a la lutracción del aco1te utilizando como solvente eter de petróleo.-Bsta extracción debe continuarse pasta que ata unas gotas del solvente proventiente del extracto no defien ningun residto al ser evaporados on un vidrio de reloj.

Conclulda la extracción del acelto electuamos la evanoración del solvente y secamos a la muestra en estufa a loos durante 5 horas; dejacios enfriar en secador de Claca y pesamos obtenlendo por dife- 
ferencla de peso la cantidad de aceite y humedad de la semilla.Iuego procedemos a la pulverización de la muestra en morteo hasta que toda ella pase a traves del tamlz standar N950, con 10 cual teneisos a la muestra en optimas condiciones de extracción.-

\section{EXTAACCIOR}

Bata muestra previamente preparada, la colocamos on un balon de 2 IItros procediendo a la extracción de las sustanclas pécticas por sucesivos tratamientos a 1009 con la solución extractorajprácticamente se requieren sels ataques,con duración de una hora,para extraer la totalidad de las sustanclas pfeticas.Durante los sucesivos ataques,y principalmente en los primeros, debe evit $r s e$ el depóslto de la muestra en el fondo del balón,por cuanto se puede producir la carbonización de la muestra, lo cual se logra mediante una agitación hasta que comience la ebullición y esto tamblen se facllita por un aumento de la masa del solvente.Las cantidades de solvente empleado en las suscesivas extracciones fueron las sigulentes:1) 160 c.c.;2\%)100 c.c. $y$ er las restantes 50 c.c.

Despues de transcurrido el tiempo de extraccion dejamos que sedimento la muestra y fillramos en calierte a través de una gasa, volviendo al balín las porciones de muestra que han quedado adheridas a la gaPSSETA sa por medio de una plzzeta,y aquellas porclones de la muestra que pasaron suspendidas en el extracto son recpperadas por contrifugaclón y relntegradas al balón.-

De la misina manera procedemos en las sucesivas extracclones, para que la totalidad de la muestra, pueda zor completalente agotada.Efectuada la extracción, reunimos 103 Ifquidos,provenientes de los sticesitros ataques, homogenel zamos por agitación,filtramos por papel al facfo, lavamios el filtro con $\mathrm{B}_{2} \mathrm{O}$ destilada y finalmente completamos el volumen del extracto a 500 cc. con $\mathrm{H}_{2} \mathrm{O}$ destilada.Con el objeto de determinar el grado de extracción que se logra mediante el emploo do los distintos agentes que se han propuesto Inaror. ensayadas las siguiontes soluciones:Acido cftrico al 0,5\% oxalato de $\mathrm{NH}_{4}$ al $0.5 \%$ y $0.06 \mathrm{~N}$.de ClH.Práctlcamente ze observó que estas tres soluciones efectian ana extracción total de las sustarclas pécticas, pues los resultados obtendel 
dos por análisis cuantitativo concuerdan estrechamente; tambien se observó que el ácldo citrico es el más diff́cil de ser eleiminado posterformente.-

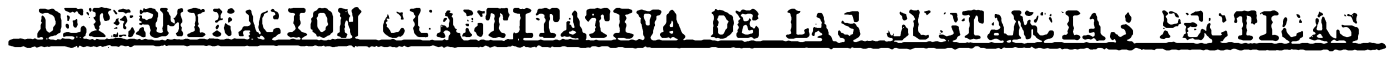
El cóntenldo de sustanclas pécticas de la semilla de lino han si:do determinados cuantitativamente al estado de pectato de ca.La deterninación del grado de exactitud de los métodos propuestos, basados en la producción de pectato de sa. se reallzó por comparación de los resultados obtenidos,por anklisis de una solución de pectina de lino extraida con ácido citrico al 05\%,mediante el emp pleo de los procedimientos de cujas técnicas han sido cltadas anteriormente, hablendose obtenido prácticamente las siguientes cifras:

Ansilisis

No

I

II

III

IV

Promedio
Pesopectate de cis.

Bmett-Carré

0.0292

0.0299

0.0303

0.0301

0.0299

0.0354

Por estos datos se aprecia la estrecha concordancla de los resultados obtenidos por el procedimiento de Bamett-Carré mlentras que los obtenldos por el procedimiento de Carreino son dispares y mas altos,por 10 cual este procedimiento fué desechador-

Los procedimlentos de Carréf-Haynes y Rmettwarré,tlenen el inconvenlente ds que $30 /$ productr pérdidas dobido al gran número de manipulaciones que requieren, pero se observó que ostas perdidas se producen principalmente durante el proceso de lavado delido a la dificultad de rechperar totalmente al precipitado de pectato de va. que queda adherido al papel de f1ltro,despues de cada una de las repetidas piltraciones 8 esta dificultad fué subsenada por reemplazar el proceso de flltración por una centrifugación.Prácticamento la deterninación do las sustarcias pécticas de la semilla de lino, de acuerdo al método de mett-carre, fue efectuada de la siguiente forma: 
Del extracto de pectina, extrafdo con solución de $\mathrm{FCl}$ al $0.06 \mathrm{~N}$, tomamos una allcuota de $50 \mathrm{c} . c$. que corresponden a $0.5 \mathrm{gr}$. de sem 1 Ila,g efectuamos la precipitación de la pectina con 4 veces su volumen de alcohol, adiclonado con una cantldad suficlerite deHil para producir una solucion $N / 10$, dejando on reposo una nocke. Separamos la pectina precipitada por centrifugación y lavamos el prec1pitado, en el tato de centrifuga,con sucesivas porcione:s de la mezcla alcohol-ácldo.colocamos el precipitado en un vaso,disolvemos con $\mathrm{H}_{2} \mathrm{O}$ destilada callente y 10 llevamos a un volumen de $300 \mathrm{cc}$. con $\mathrm{H}_{2} \mathrm{O}$ destilada se neutraliza con Ha.OHqutilizand como indicador fenolftaleina y luego se adlclonan 100 c.c.de $\mathrm{NaOH} \mathrm{N} / 20$ dejando en reposo una: noche.-

Transcurrido este tiempo,se agregan $50 \mathrm{cc.de} a ́ c i d o$ acetlco R.dejando on reposo 5 minutos, luego se adlcionan 50 ca.de Ciscia.M, dejamos reposar una hora y finalmente calentamos a ebullición por 3 minutos.-

Separamos el precipitado de fectato de ca.por contrifugación y io lavamos, en el mismo tubo de centrifuga con $\mathrm{H}_{2} \mathrm{D}_{\text {callente a no reaa }}$ ción de cloruros.-

Transferimos el precipltado a un vaso,suspendiéndolo en $\mathrm{H}_{2} \mathrm{O}$ destllada,se hierve por 3 minutos,y nuevamente separamos el precipl tado por centrifugación,y en el liquido separado investigamos claruros.Este paso debe repetirse hasta que el liqurdo de edeshacho no presente reacción de cloruros.Luego pasamos el preclpitado de pectato de ca. a un vaso,10 suspendemos en $\mathrm{H}_{2} \mathrm{O}$ destilada,filtramos por papeles pareados,saca-: mos en estufa a $100 \%$ durante 12 horas,dejamos enfriar secador de $\mathrm{CI}_{2} \mathrm{Ca}$. y finalmente pesamos.-Para obtener el peso de la pectina en base al peso del pectato de Ca.hasta multipllcar a est. te Ultimo por el factor 0.923.-

De cada una de las variedades de semilla de lino se efectuaron3 extracciones distintas y sobre cada una de estas se efectú un análisis por triplicado y cuyos resultados son los siguientes: 


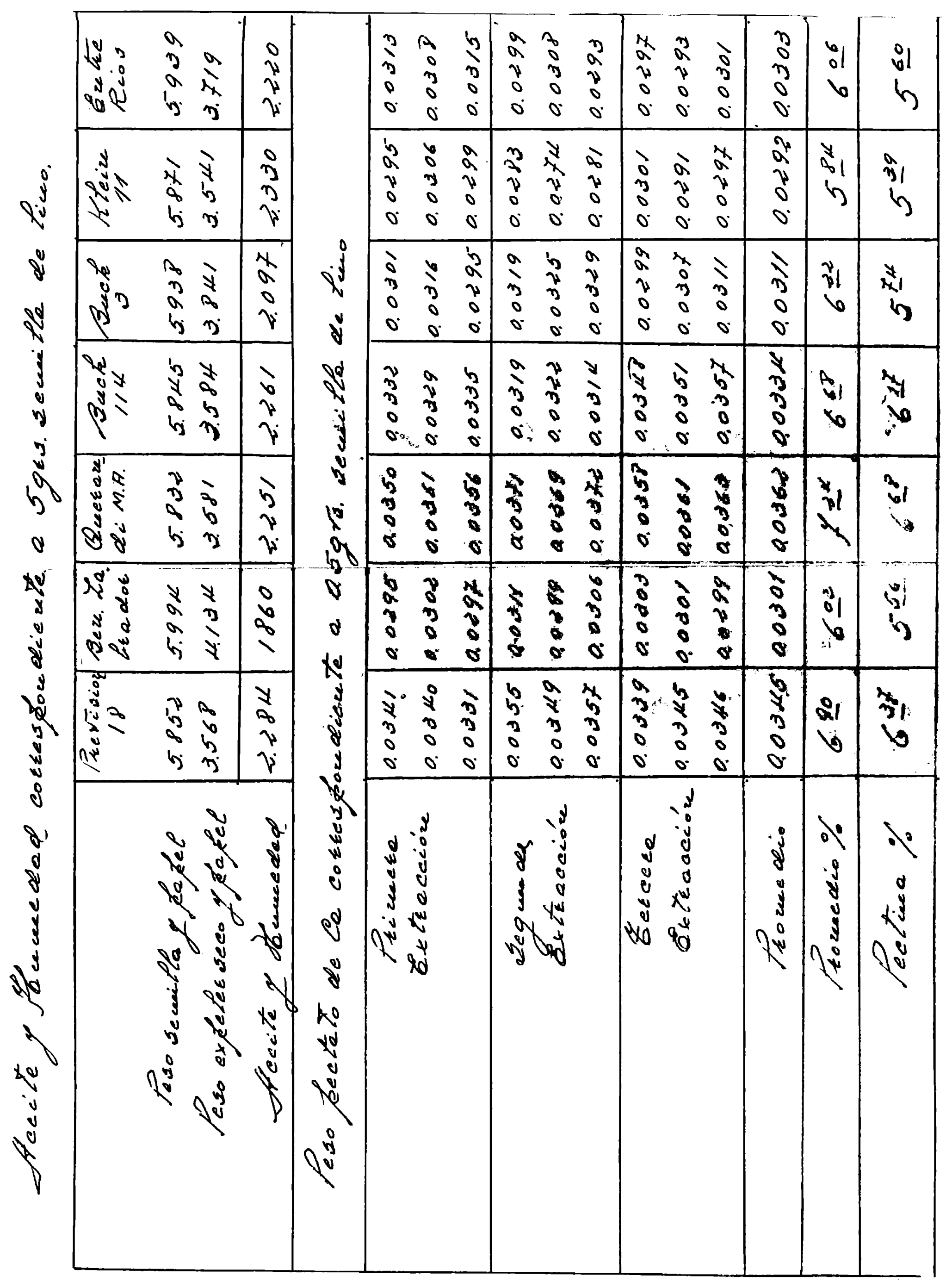




\section{CAPITULO III}

BXTRACCION DE PETINA DE LAA SEMILIA DE IINO

Para la obtención de la pectina de la semilla de lino,con el obfeto de estudiar su composición química y su capacidad de formar geles de azúcar-ácldo- $\mathrm{H}_{2} \mathrm{O}$,procedemos previamente a la preparacion de la muestra.-

La semilla de lino es mollda,desengrasada,secada y pulverizada en Igual forma que la descripta en el captulo anterlor.-

Iuego el expeler seco es colocado en un balón al cual ze le adppta un condensador a reflujo y es extractado con sucesivas porcionos de alcohol etrilico a 950 en callente.-

Esta operación tlene por objeto eliminar aquellos constituyentes de lasemilla, que son solubles en este solvente,y que son diffelles de eliminar cuando han sido extrafdos conjuntamen'te con la pectine (17-58).-

\section{EXTRACCION.-}

Con el objeto de obtener una pectina de optima calldad es recesario regular chidadosamente, durante todo el proceso de extracción; Iths sigulentes factores:concentración de la solución extractoras: tiempo de extracción y temperatura,segón lo recomendado par 1 Kosos autores(6-37-50-53-55-58-60-74-85-86 etc.).irácticamente za extracción se realizo de la slgulente maneraz Cincuenta gramos de expeler,previamente preparado, fueron extractia

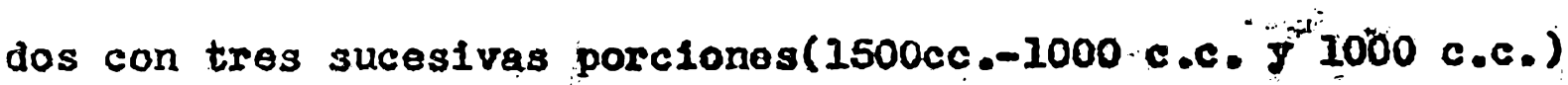
de una solución $0.01 \mathrm{~N}$ de $\mathrm{Cl}$ d duranto $30 \mathrm{minutos}$ a una temperatíra de 908c.-

Conclufda la extracción reunimos log extractos y los dejamos on: reposo 12 horas para que sedimenten las pequerias particulas do la semilla que se encueritran suspendidas on el extracto.Irego,prevla decantación del extracto, procedemos a su riltración al vaclo,prinero a trafís de un género $y$ par último a través de dos géneros que contiente en su intermedio uma delgada plancha de algodớn.-

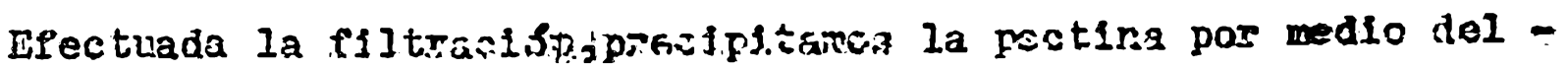


alcohol etflico (5-46-50-97-104-126) que es agregado poco a pocoy agitando sobre el extracto de pectina (17-53), dejando reposar 12 horas y luego sepatamos la pectina precipitada por 11ltración a través de vna gasa.-

Esta pectina asf obtenida contiere una apreciable cantidad de sales y para su determinación tomamos una parte alicuota,le colocamos en un crisol, la secamos a 1009C calcinamos y pesamos:

Peso crisol + pectina seca $22,3194 \mathrm{gr}$

Peso crisol $20.2194 \mathrm{gr}$

Pectina seca

$2.1000 \mathrm{gr}$

Peso crisol + cenlzas

20.3962

Peso crisol 20.2194

Peso centzas correspondiente a $2.10 \mathrm{gr}$ pectim 0.1768 Contenido de cenlzas: $8,41 \%$

Con el in de disminutr este ato contenido de cenizas, disolvenos la pectina restante en $\mathrm{H}_{2} 0$ destilada $\mathrm{j}$ sometemos a esta solución a un proceso de electrodlalisis (46).-

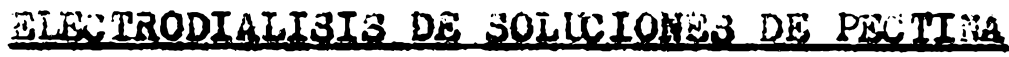

El electrodializados es uri aparato que está constituido por una cámara,que por intercalación de las memebranas,queda subdividido en tres compartimentos, de los cuales, los externos están ocupados por los electrodos y el central por la solución de pectina.En este proceso se utilizaron electrodos de $\mathrm{Pt}$ y $\mathrm{HI}$ en forma de discos, como ánodo y cátodo respectivamente.-Estos electrodos se encuentran conectados a un clrculto on el cual se har intercilado un voltimetro, un millamperfmetro y una resistencla que permite rogular el potenclal de la corriente entre o y 225 volts,segin se puede apreciar en el siguiente esquens:

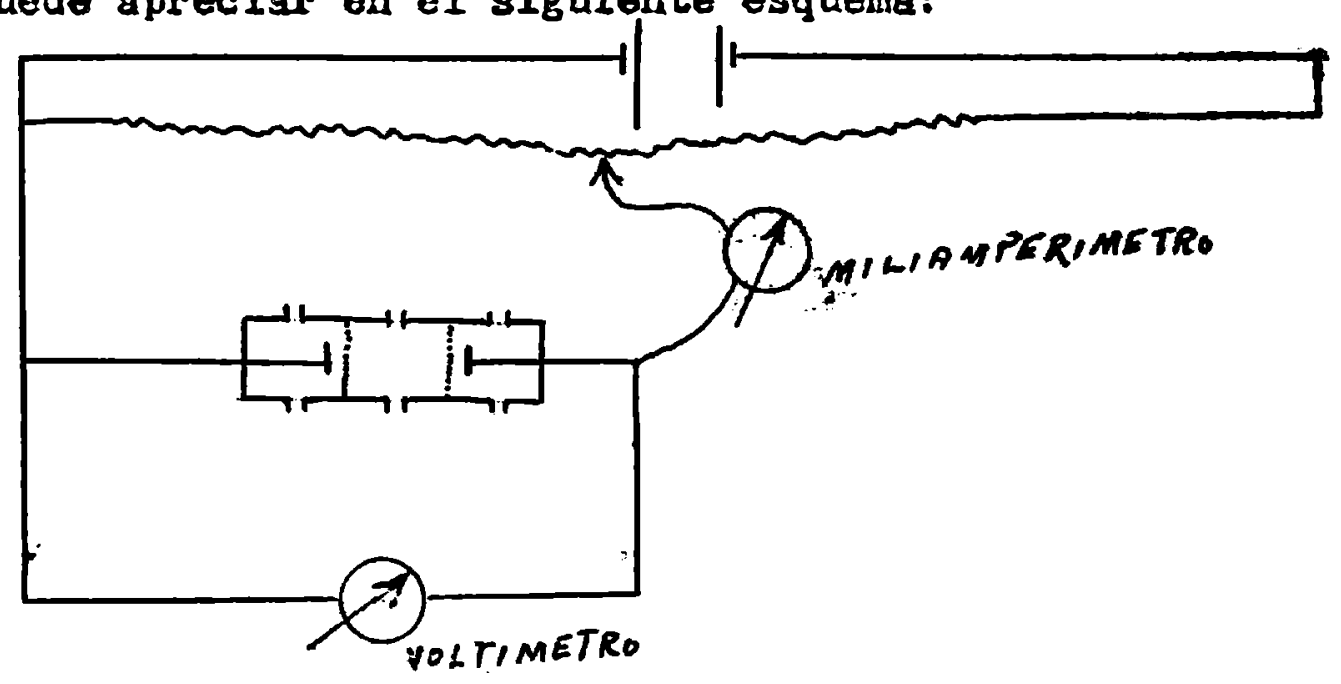


in las primeras tentatiras de ensayo,para la utilización je este proceso,se emplearon muestras de pectina más o menos degradadas Y la electrodialisis de efectuó a través de membranas de pergandno, con la solución mantenida on reposo.Durante el transcurso del proceso se observó que al princlpio del mismo se producla un desphzamiento de la pectina sobre la mobrana correspondierte al cátodo, iero posteriormente esta migración se invertra,es decir,el depósito se formaba sobre la menebrana que delimita al ánodo, $\mathrm{J}$, adomás se observo, que durante el proceso la membrana catódica era atravezada pof una porción de sustancia colo1dal de fuerte poder espunigeno, que con el tiempo floculaba.A continuación se transeriben las varlaciones ae la intensidad de la corriente, en frución del potenclal y del tiempo,durante la electrodiálisis efectiada en reposo y empleando membranas de pergamino:

\begin{tabular}{|c|c|c|c|}
\hline Volts & Hora & Imperaje & Observaciones \\
\hline 10 & $10 \mathrm{hrom}$. & 0.0001 & No hay desprendimlento en catodo. \\
\hline 20 & & 0.0005 & \\
\hline 30 & & 0.0010 & \\
\hline 40 & & 0.0018 & Comlenza desprendimiento gazeoso er \\
\hline 50 & & 0.0028 & cátodo \\
\hline 60 & & 0.0037 & \\
\hline 70 & & 000050 & \\
\hline 80 & & 0.0057 & \\
\hline 90 & & 0.0065 & \\
\hline 100 & & 0.0072 & \\
\hline 110 & & 0.0077 & \\
\hline 120 & & 0.0085 & \\
\hline & 10h.35min. & 0.0105 & \\
\hline & 10,40 & 0.0180 & \\
\hline & 10,45 & 0.0250 & \\
\hline & 10.50 & 0.0290 & \\
\hline & IIhs. & 0.034 & Comlenze pasaje de cololde al cato \\
\hline & 11,10 & 0.035 & do.- \\
\hline & 11.20 & $0.037:$ & \\
\hline & 11.30 & 0.0378 & \\
\hline
\end{tabular}




\begin{tabular}{|c|c|c|c|}
\hline \multirow[t]{3}{*}{ Volts } & Hora & Amperaje & Observaclones \\
\hline & 12 & 0.0388 & Desplazamiento pectina sobre \\
\hline & 18 & 0.0164 & catodo.- \\
\hline $22 \dot{5}$ & $9 \dot{\mathrm{h}}$ & $\dot{0} \dot{0} 1 \dot{2} \dot{\theta}$ & Comlenza rloculacion del colol \\
\hline & IEh & 0.0721 & do que atraveso membrana cato- \\
\hline$\dot{2} 2 \dot{5}$ & $9 \dot{h}$ & 0.0்தंs & \\
\hline & $22 \mathrm{~h}$ & 0.0085 & \\
\hline $2 \dot{25}$ & $\dot{2} 3 \dot{h}$ & $0.003^{\circ}$ & $\begin{array}{l}\text { Desplazamierto pectina sobre - } \\
\text { anddo.- }\end{array}$ \\
\hline
\end{tabular}

Ba posteriores experienclas se evitó tanto el depósito de la pectina sobre las membranas, lo cual dificulta el pasaje de los 10nes, c0mo el pasaje de cololdes a la región catódica por ofectuar la electrodílisis mantentendo la solución en constante agitación y 10 segundo mendiante el reemplazo de las membranas de pergemino por una de celorán o mejor aún por una de celofan colodien.-

E.jta membrana de celofan colodion se obtuvo por lnmersión de una LAMINA DE CELOFRN EN UNA

solución al 28 de colodion, dejándola luego secar a temperatura am-

blente.-

daemás, por efecto de la intensidad de la corrionte se pürede producir un calentamlento de la solución, el cual puede ser raducldo por colocar a ambos electrodos 10 más juntos posibles (46). - in el caso presente, la pequeña elecación de temperatura que se pròdujo fué neutralizada por exposiclón del diallzador a una corrlente do alre. Práctlcamente, la electrodialisis se efectub de la sigulente manera: Colocadas las membranas de celofan colodion procedemps a llenar las compartimentos externos con $\mathrm{H}_{2} \mathrm{O}$ destilada $\mathrm{y}$ el central con la solución de pectina,ponemos en marcha al agitador mecánico,cerramoz el ci circulto y lentamente vamos aumentando el voltaje,notándoso que el desprendimiento gaseoso comlenza en ol catodo cuando el potenclal es de35,6 volts correspondiendo a una intensidad de 0.001 amperes, hasta alcanzar una intensiciad de 150 millamperes.El $\mathrm{H}_{2} \mathrm{O}$ destllada de los electrodos fú camblada cada 8 horas y el proceso se continuó hasta que cesó por completo el desprendimiento gaseoso en los electrodos y el amperaje habla disminuido casi a 0. A continliación se citan las varlaciones de la litansidad de la co-rrionte, en funcion del potencial $\mathrm{y}$ del tjempo, durante is electrodla 
Ilsis efectuada con la sulución cantenida en constante agitación y expleando membranas de celofan-colodion.-

$\begin{array}{ccc}\text { Joltaje } & \text { Tiempo } & \text { Mllamperes.- } \\ 120 & 0 \text { horas } & 3 \\ 125 & 10 \text { n } & 149 \\ 168 & 20 \mathrm{~g} & 153 \\ 225 & 40 \mathrm{n} & 147 \\ 225 & 60 & 116 \\ 225 & 100 & 0.6 \\ 225 & 110 & 0.25\end{array}$

Luego de esta solucion electrodilizada,precipitamos la pectina por medio del alcohol etflico a $96 \%$,separamos por flltración a través de una gasa,deshldratamox por sucesivos lavados con alcohol absoluto,secamos eb estufe a una temperatura no superior a $509 \mathrm{C}$, pulveri zanios en mortero y finalmente se tamiza.-

ACIDO GalactironICO: El ác1do galacturónico fú determima do par el dosaje del $\mathrm{CO}_{2}$ desprendido, por decarbozllaclón del mismo, al ser calentado con $12 \%$ de $\mathrm{C} 1 \mathrm{H}$ eurante 6 boras.Luego la cantidad de $\mathrm{CO}_{2}$ determinada se multiplica por el factor 4,4 (Tollens-Leferro),ALIDC ACETICO: Saponificamos la pectina con lia OH,acidiflcamos con vapor de agua y valoramos el ácido acético con solución de $\mathrm{Na} . \mathrm{OH} 0.05 \mathrm{~N}$. PENPOidi: Fueron determinadas por la evaluación del furfurol,que se produce al destilar la pectina con solución al lés de Eci,al estudo de furfurolfloroglucida,previa deducción de la cantidad de furfurol-floroglucida correspondiente al ác1do galacturónico. Esta cantidad es de una parte de furfurol-floroglucida para 2,64 partes de ác1do galacturónico (Tollens-Krurger-Krober).-

AlcoHOL Serfifio: Saponificamos la pectina con alcall,acidiflcamos. $y$ destilamos el alcohol metilico deterninandolo colorimstricamente con el reactivo de Denfices.-

ACIDEij: POr titilación de Lra solución de pectina al 14 con solucion $N$ de RaOH usando como indicador solución alcohólica de renolftalelna.-

Todas las soluclenes valoradar jue se wir empleach an i- peesante 
trabajo, de acuerdo a 10 recomendado por Furman (54) ban sidopreparadas a partir de la solución patron ácida de ftalato HK por ser esta sustancia anhidra,de alto peso molecular y no ser hidroscópl ca.-

A continuación se dan los porcentajes obtenidos experimentalmente:

Humedad 10.02

Cenizas 023

Aclaes

0.65

Acido galacturónico

72.48

Acldo acético

5.76

Pentosas

7.44

Alcohol metilico

5,31 .

Galactosa:Por diferencia a 100:

9.01

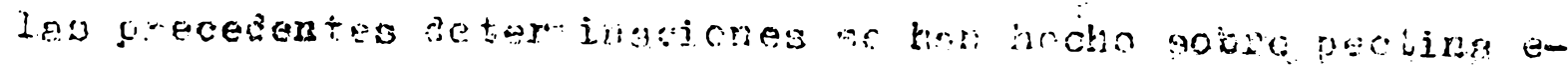

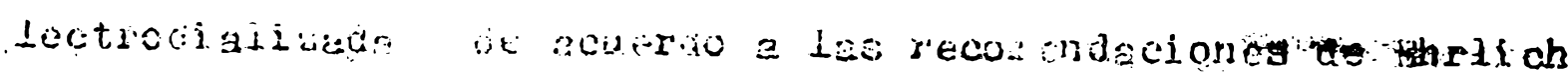
y de 


\section{DE LINO}

Ia determinación de la fuerza de la jalea de la pectina de lino ha sido realizada, empleando un aparato similar al sugerido por Baker (5), en base a la determinación de la presión que se necesita ejercer para que el embolo de una jeringa penetre a traves de la jalea. Eil aparato,puede ser esquematizado de la siguiențe forica:

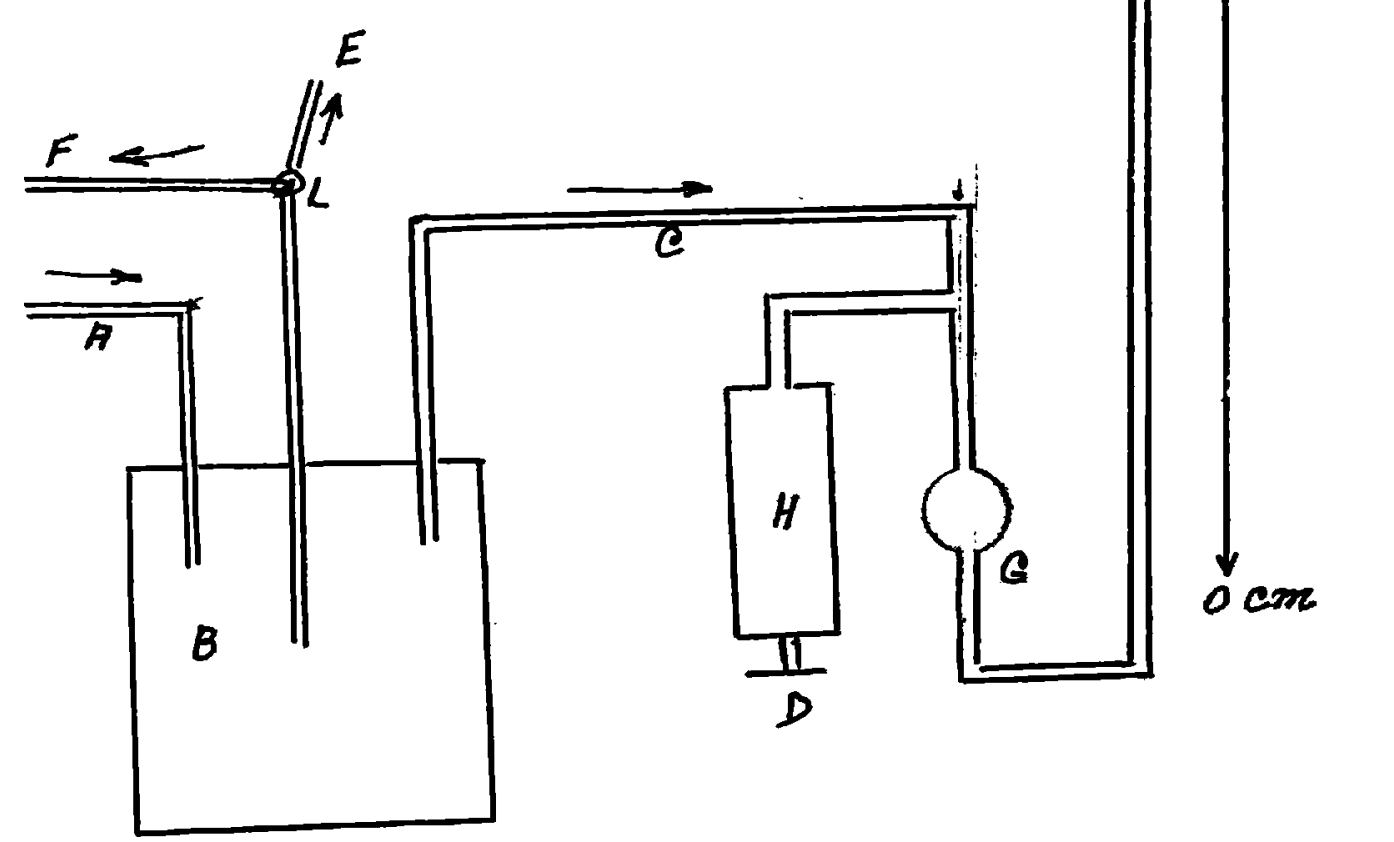

Por el tuko $A$ entra el $\mathrm{B}_{2} 0$ al houlf de 2 lltros; if es una 1lave de tres vias que permite por la salida E llevar el sistema a equilibrio y por la salida F perrite evacuar el exceso de $\mathrm{H}_{2} \mathrm{O}$ con el objeto de tener slempre en el wouls un nivel cosstanie de $\mathrm{R}_{2} 0_{-}-\mathrm{El}$ tubo o transflere el aire desplazado al manómetro G y a la jeringa H.-

Fa entrada de $\mathrm{H}_{2} \mathrm{O}$ por el tubo i debe ser regulada de tal manera que el manometro al cabo de un minuto,alcance una altura de $30 c i$. estando el ambolo apoyado a una superficle flerme.-Desples de cada determinación por medio de 13 sallda $\mathrm{F}$, debe lievarse a un nivel constante al $\mathrm{H}_{2} \mathrm{O}$ contenida en el joulf para tener slempre ura prom sión constante.-

Para efectuar estas deterrinaciónes,Baker no utilizó ninguna Iubricante en la jeringa, pero en el presento trabajo el emploo de para- 
fina llquida,a tal fin,fue imprescindible.Aderás de esto,el presente aparato diflere del ideado por Baker tanto en los diámetros de los tubos de conecclones como en la superficle del embolo de la jeringa que se utiliza para perforar la jalea.-

Bitas diferenctas fuerpn subsanadas por comparación de los resultados obtenidos,mediante el empleo de este aparato, sobre una jalea preparada con pectina de Iino $\bar{J}$ otra preparada $\theta$ :. Ldéntica forma con pectina de manza:.a de procedencia norteamericana, cuyo contenido de cenlzas era de $0.7 \%$ y una humedad de $14,07 \not$.-

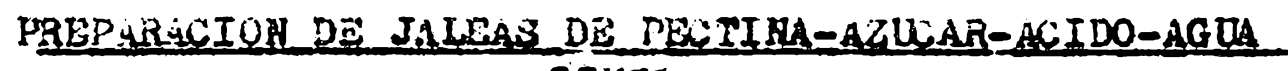 jigutendo las Indicaciones de BAKEr las faleas de pectina, de Iino} y de manzarias, fueron preparadas de la slaulente forma: Pesamos exactanente $1 \mathrm{gr}$. de pectina y lo disolveras een $100 \mathrm{cc}$. de $\mathrm{H}_{2} \mathrm{O}$ destilada y adiclonamos 10 cc.de ác1do tártrico H/10.- Bobre esta solución de pectina deteminamos su escosldad relativa y su $f . H$ habiendose obtenido $l 0 s$ sigl lentes valores:

$$
\begin{array}{cc}
\text { f.H.a 2600. } & \text { Visc.rolat.a 260C. } \\
3,32 & 8.6 \\
3,2 & 7,8
\end{array}
$$

Pectina de manzanae

$3,32 \quad 8.6$

Pectina de Iino

La viscosidad relativa fue determinada por medio del viscomimetro de Ostwald y el p.li. fue determinado potenclomstricamente, habléndom. se utillzado como buffer de $\psi_{\text {.H. }}=\psi$ la siguiente solución:

$$
\begin{array}{lr}
\text { Fitalato acido de } \mathrm{K}^{\mathrm{ij}} / 5 & 50 \mathrm{c.c} . \\
\mathrm{Na} \text { or } \mathrm{H} / 5 & 0.4 \mathrm{c.c} . \\
\mathrm{H}_{2} \mathrm{O} \text { destilada } & \text { c.s.p. } 200 \mathrm{c.c} .
\end{array}
$$

Luego la solución de pectina se completa a lin volímen de 120 c.c. con $\mathrm{H}_{2} \mathrm{O}$ destilada y se coloca en una cópsula tarada,so callenta $y$ cuando comienza la abuilición de la soluctón so lo agregan $100 \mathrm{gr}$. de azúcar y se continúa el calentamiento a obullición hasta que la. mezcla pese exactamente $144 \mathrm{gr}$. ?

Luego la jalea sué colocida en carsulas de petri,so tapa y se doje durante 2 is horas.in todas las determinaciones se utillzaron cápsu-las de Petr1,-iderticas 


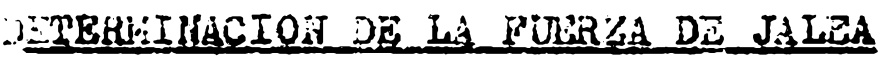

Previameta regulamos la corriente de $\mathrm{IF}_{2} \mathrm{O}$ qo entra en el prasco de joulf de tal manera que $\mathrm{e} \perp$ mansmetro,estahdo el ́bmolo $\mathrm{D}$. apoyado sobro superficie firme,res̆lstre una altura de $30 \mathrm{~cm}$ al cabo de $I$ nlinuto,-Despues Ilevamos el $\mathrm{H}_{2} \mathrm{O}$ conteriáa en el -Woulf a ivel constante mediante la sallda F.Lueso colocamos la jalea bajo el embolo D.cerramos la llave L. y dejamos ascender la presión hasta que el embolo perfore la superficie de la jalea.-bin ese instante se lee el monetro,el cual nos fa la fuerza relativa de la jalea en contlmetros de presión de agua.-

A continuación se transcriben los restiltados pronadios de 10 determinaclones efectuadas sobre jalea de pectina.de manan y de pectina de lino,dizlizada y sin dializar:

iltira dn cm.deí manowdtro

Pectina de manzana

m

n
" lino dializada

40.6

38.8

" no diallzada.- 
1) La extracción de las sustanclas pécticas de la semilla de lino con solución $0.01 \mathrm{H}$.de CIH a 9000 . y por periodos de 30 minutos di6 excelonte resultado.-Por aumento de los factores,concentración de 19 solución oxtractora, temperatura y tidmpo de extraccio 3e obtelene ung mayor cantidad pero la pectina resultante será mas o menos legradada,mientras que la extracción acuosa da escaso rendinfento. En el proceso de extracción de la pectína,para su evaluación cuantitativa se ha utilizado la solución $0.06 \mathrm{~N}$. de CIF para facilitar la filtración del extracto,pues a esta concentración se aprecla una dosminuclón de la viscosidad.-

2) Experimentalmente el método mopuesto por Emett-carró,para Ia determinación del pectato de ca. dió los jores resultados mientras que por el procedimlerto utilizado por carva ino se obtiener valores dispares y stpericres a los obtenfios mediante el nétodo propiesto por y Carré.-

3) Ia semilla de lino,despues de haber sldo extraldo su aclete,es una buena fuente para obtener pectina, ya que el expeler seco contiene aproximadamente un $10 \%$ de pectira.-

4)Zl vejor procedimiento para la eliminación de las sales conterildas for la pectina es por electrodiallisis.-

5) La membrans de celorán-colodion,empleada en dicho proceso, fue la quie dió los rejores resultados.-

6) In el aparato empleado on estas experienclas, efectuando la electrodiálisis con zna intensidad de 150 miliamperes, no se modujo un mayor calentamiento. -21 H $\mathrm{H}_{\mathrm{C}} \mathrm{O}$ destilada proventente del cowrertamento catódico dló fuerte reacción cualltatita de $\mathrm{X}$. s ca.

7) La pectina obtenida de la samilia de ilno es de color blanco pero comparada con la pectina de manzana nor teamericana presenta un levisimo tinte más ascuro que eista iltim.82) Por comparación de los restitados obtendios experimentalnente sobre faleas preparadas, en lguales condiclones con pectinade lino y pectina de manzana,se llega $a_{\text {l }}$ la conclusión de cue ambas tienen un poder de falea similar.-

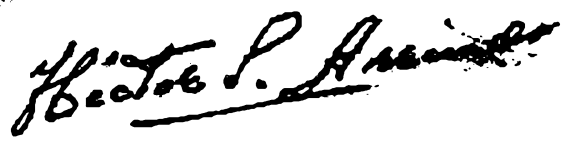




\section{Seftiografie}

IND. CHEM. CA. IND.

1) Ahrann C. and Hooker.H. Ynd. Dne.Chin 18-412-1926

2) Allen H. Botan.Gaz. 32-1-1901-

3) ALdersor E. Y.BIol.Chom. 122-531-1936 IND

4)Bater w. and filison C. Ira. H.E. Cher ed. 33-1941

5) Baker G. Ind. InE. Chen ed. Ann. 18-89-1926.-

6) Baker G. and Narvin W. Del. Agr. Fxpdt.5ta. 234-1941

7) Bell,N. Sci. Froc. Bog. Dublin Soc. 14-349-1915: Chem. Abat. 10-205-1916

8) Bauer K. Chem. Zentr. 72(2)-196-1901.-

9) Baur 2. คnล Ink X. - J. 3101 . Cbem 100,-293-1035.

10) Berveu G and Jones J. -Cheristry c Ird.363-10;0

11) Beremann $\%$. and Wachemer Y. - Ber-63-316-10xn

12) Bie. C. Tan der whem. Teekblad 32-55?-1035.-The lnalyat 60-557 $10 \times 5$.

13) Eertrand 6. et.rol1évre A. -Corpt. rend 1.10-1012-199.; 120-110$1895 ; 121-726-1005 .-$

14) Bock I.. Elnsele 3. Ang . Shem.53-132-1940; cher: Abstr.35-9c8-941

15) Is ck H.and Winsele R. -J.Frakt. Chert 155-225-1940; Chell. Abstr. 34-65.75-1940.-

16) Eonner J. Rotar. Rev. 10-475-1:36;froc.Acad. Sc1. Amsterdan $38-346-1935 .-$

17) Bourquelot E. and Herl say H. - J. Fharc. Ch1m.ser.6-473-1898.-

18) Bowan, J. and HC. IInnis R. J. Amer. Chen. Soc,52-1209-1930.-

19) Braconnot H. - Ann. Chir . FHy B. 30-96-1825.-

20) Branfoot y. Special Report. $\$ 333$ Pood Juv.Board Dep.of Sal and

Ind. Reverich Jondon The Anaigat 54-594-1929

21) Buston, Fand Nouj1 H. - Bincher J. 26-2n90-193?.-

22) Candlin, S. ard Schryver S. Froc. Roy soc, Ionion 103-365-1928

23) Carre I. Elochem J. If-704-1022.-

24) Carré: Biochem J. 19-257-19?5; Ane. Bot. 39-811-1925.-

25) Carre H. and Havres D. Plocher J. If-6n-10??.-

26) Carré . and Forne A. Ann. Bot. 41-103-15i27.-

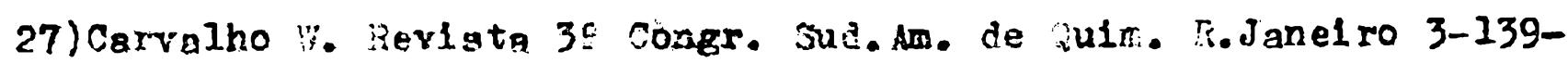
$1937 .-$

28) Chernot 2. Pood J.18-200-1923.-

29) Clay 80: noNorris F. and scheyter. i. Blochem J.-15-643-1921.-

30) Conrad C. J. An. Chem. S0c. 53-1999-1931.-

31) Cowgil1 H. V.s.Paten 1.973.614.-

32) Cruwss Fand KC.KaIr J. Ind.Er:G. Chem Id.Ind..8-417-1916.-

3x) Daughterg 1. Bxpdt. Sta. Record 59- 713.-

34) Devisen Fand ill leman J. Botan. Gaz. 83-329-1927.-

35) DIkson 1.-Ottersor Hsrd IInt K. J.Ak. atom. Soc.52- 775-1030

36) Dore . Ira. The. Cham. Tr.Jur. 14-jrA2-1024.-

37) Shrlich ?. - mimann 11-257-1033

38) Ehrlich F. - 1 1ocher 250-5? -1032; 251-2rA-1032.-

39jEhrlich $\mathrm{P}$ - Z. Aneew Cher ar-1305-1927.-

40) Fhrlich F. and fisensel R. Biocher z. 291-93-1035.-

AI) Ehrlich F. Koswahly A. Bionhen Z. 212-162-1929 
42) Fhrlich F. Bchubert F. B10chem Z. 169-13-1926.-

43) Ehrlich F. Schubert F.Blochem Z.203-343-1928.-

44) Ehrlich F.Schubert F. Ber- 62- 1974-1929.-

45) Ehrlich F.Sommerfeld R. Blochem Z. 168-263-1926

46) Bnmett A. Blochem J.20-564-1926.-

47) Emmet A. and Carre K. Blochem J. 20-6-1926.-

48)Espinosa B. Tesis-Facult Quim. F Farm.La Plata.-

49) Fellenberg T.Von Chem.Zeútr. 19-942-1914-

50) Fellenberg T.Von Blochem Z. 85-118-1918.-

51)Fellers C.and Griffiths F.Jud.Eng.Chem. Ed.Ud.20-857-1928.

52)Felirs C.And Rice C. Jud. Eng .Chem.Bd.An.4-268-1932.-

52 'bis) Felser H. Chem.Zentr 1-2270-1942 Chem Abstr.37-3275-1943

53) Fremy B. Ann.Chim. Phys .24-5-1948 y Pharm.Chim.26-368-1840:-

54) Furman N. Willard H.An Iisls Quim.cuantitatigo...1935.-

55)Gaddum 2. Florida Agr.Sta. Tech.Bull 268-1934.-3;

56) Goldthwaite H. Ind. Eng.Cher. Ed. INd. 1-333-1909-;"2-457-1910.-

57)Gortner R. and Hoffman W. U.S.Patent.1.915.568-1933.-

58)Griggs M.and Johnstin. R. Jud. Fng. Chem Ed.Jud.18-623-1926.-

59)Halliday E.and Bailey G.Jud. Eng .Orem Ed.Jud.16-595-1924.-

60)Hardy F. Blochen J. 18-883- 1924

61) Haynes D. Blochem J.-8-553-1914

62) Henderson S. J.Am.Chem.Soc .1928-2117-1928.-

63) Henglein B.and Schneider G. Ber-69 B-309-1936; Chem Abstr.30-

$$
\text { 3780-1936.- }
$$

64)Hrrzfeld A. Chem.Zentr. 62-618-1891.-

65) Jameson E. Jud. Eng.Chem. Ed.An. 17-1291-1925

66) Johnstin R. and Denton M.Jud. Bng .Chem. Ed.Jud.15-778-1923.-

67)Kerr T. and Bailey I. J.Arnold Arboretum 15-327-1934;16-273-1935

68)Kertersz Z. Hew York Agr. Expdt. Sta.Bull 589-1930.-

69)Kuaggs J. Mannign A.and Schryver S. Blochem J. 17-473-1923-

70)Kopaezewski W. BuRz.Soc .ChIm. Bía? 7 7419-1925.-

71) Lefévre K.Tollens B. Ber-40-4513-1907.-

72) Leo H.-Taylor C.Lindsey J. -U.S. Patent 2.367.132:Chem Abst.39-

2358-1945.-

73) Luers H.-Lochmuller K. Kolloid Z. 42-154-1927.-

74) Ludtke H.and Felser H.Ann 549-1-1941:Chem.Abstr.37-4368-1943.- 
75) Mang in L. - J.Botan. 5-400-1891; 6-206-1892;7-385- 1893.-

76) Mc .Kinnis R. J.Am.Chem.Sc .50-1911-1928́.-

77) Meht1tz A.von - Konserven Jud. 12-229-1925:Chem.Abst.20-1474

$$
\text { 1926.- }
$$

78) Mehlitz A.Von Konserven Jud. 12-467-1925: Chem .Abst.20-2547-1926

79) Mehlitz A.Von Kolloid Z. 41-130-1927

79 B) Yeyer K. and Kark H.Ind.Eng.Chem.Ed.Ind. 22-1415-1930

80) Morell S.Baur I. and Link K. J.BLOI.Chem.105-1-1984.-

81) Morell S.and Lincik K. I.BLol.Chem.100-385-1933.-

82) Wers P.and Baker G. Delaw.Agr .Expt.Sta.Bull.144-1926

83)Myers P.and Baker G. Delaw Agr Expt.Sta.Bull --149-1927

84.) Muers P.and Baker G. Delaw Agr. Expt.Sta.Bull -160-1929

85) Myers P.and Baker G. Delaw Agr.Ixpt.Sta.Bull -187-1934

86)Myers P.and Baker G. Delaw Agr.Expt.Sta.Bul1168-1931

87) Naûj1 D. and Norman A.Blochem J. 22-596-1928.

38) Naû́f1 D.Patou, F.and Iing. A.J.Soc.Chem.Ind. 44-253-1925

89) Nomenchaltura of Pectin I.Am.Chem.Soc.43-Proc.38-1927.-

90) Nomencilature of Pectin Chem. and Ing. News 22-105-1944.-

91) Norman A. Blochem J.22-749-1928.-

92) Norman A. and Martin J.Blochem I. 24-649-1930

98) Nelson E. I.Am.Chem. Soc. 48-2945--1926.-

g) F. Blochem I. 23-195-1929.-

95) Norris F.and Resch C.Blocherm.J.29-1590-1935

96) Norris F.and Schryver S. Blochem.I.19-676-1925

97) Norris F. Biochem I.20-993-1926

98) O'Dwyer M.B1ochem.I.19-694-1925

99) 01sen A.Ind. Eng.Chem. Ed.Ind. 25-599-1982

100)0lsen A.Stuewer R.Fehlberg E. and Beach N. Ind. Eng.Chem. Bd. In 31-1015-1939.-

101) Ohn A. Ind.Eng. Chem.Ed.Ind.18-1295-1926; 22-635-1980.102) Payen A.Ann .Chim. Phys . 26-329-1824 .-

103)PItman G.and Brness W.Ind. Bng .Chem, Ed.Ind. 21-1293-1929

104) Poore H. U.S.Dept.Agr.BuIf Les

105) Precce I. Blochen.I. 25-1304-1931.-

106\$B) Ruschman G. y Bartram H. Zentr. Bakt.Paras1tenk. 102-3

361-1940-Chem.Abstr .35-908- 1911.-

106) Schneider G.Chem. Eng. News 15 W220-453-1937.- 
107) Schne1der G.and Fritschi.0. Ber-70-2537-1937.-Chem Abet. 311370-1937

108) Schne1der G.and Fritschi.U.Ber-70-1611-1937: Chem.Abstr.31-7400 1937.-

109)Schnelder G.and Bock.H.Her-70-1617-1937; Chem.Abst.31-7400-1937 110) Schelder G.and Eock.H.Ber-71-1353-1938:Chem. Abst.32-7415-1938 111)Schnelder G.and Zlervogel M.Ber-69-2530-1936-Chem.Abst.31-1369 1937.-

112) Schryver S.and Eayner D.B10chem I.10-539-1916.113) Sermichon L. Chimis e Industrie 17-25-1927-

114) Singh L. Ind. Eng .Chem.Ed. Ind.14-710-1922.-

115) Smlth F. I.Chonistry a Ind. 363- 4-1939

116) Spender G/ I.Phis .Chem 34-410-1930

117) Stuewer R.-Beach N.and Olsen A.Ind.Eng.Chem.Ed.Am.6-143-1934 118) Sucharipa R. I. Asoc offlcial Agr. Chem.7-5R-1983- I.Am.Chem. Soc .46-145-1924.-

119)Tarr.L. Delaw Agr. Expt. Sta.Bull 131-1923.-

120)Tarr. I. and Baker G. Delaw Agr. Expt. Sta.Bull 136-1924,142-1926 121)Tromp.H.and Tollens B. Ann. X.Liebigs 286-278-1896.

122-)Tutin F. Blochem I. 15-494-1921

123)Tutin F. Biochem I. 17-510-1923

124)Tupper-Careg. R.and Priestley I.Proc.Rol. Soc.Iondon 95-109-92. 125) Van Iterson G.Chem Weekland.30-2-1933- Chem.Abstr .27-1504-1235 126) Wichmann H. J.Assoc . Off .Agr .Chem.6-34-1922; 7-107-1923;8-128 1924.-

127) Willaman I. Botan. Gaz. : 83-329-1927.-

128)Willemen I.and Kertesz Z.New Yoxk AGR.Expdt.Sta.(Genova) Tech. BuI1.178-1931.-

129) Willlams K.and Johnsor C.Ind. Eng.Che ... Ed .An.16-23-1944.130) wilson C. Ind . ing . Chem. Ed. Ind .17-1065-1925.131)Wilson C. Ind.Eng.Chem.Ed.I d.20-1302-1928.- 